\title{
Urocortin 3 Modulates Social Discrimination Abilities via Corticotropin-Releasing Hormone Receptor Type 2
}

\author{
Jan M. Deussing, ${ }^{1}$ Johannes Breu, ${ }^{1}$ Claudia Kühne, ${ }^{1}$ Magdalena Kallnik, ${ }^{2}$ Mirjam Bunck, ${ }^{1}$ Lisa Glasl, ${ }^{2}$ Yi-Chun Yen, ${ }^{1}$ \\ Mathias V. Schmidt, ${ }^{1}$ Regine Zurmühlen, ${ }^{1}$ Annette M. Vogl, ${ }^{1}$ Valérie Gailus-Durner ${ }^{3}$ Helmut Fuchs, ${ }^{3}$ Sabine M. Hölter, ${ }^{2}$ \\ Carsten T. Wotjak, ${ }^{1}$ Rainer Landgraf, ${ }^{1}$ Martin Hrabé de Angelis, ${ }^{3,5}$ Florian Holsboer, ${ }^{1}$ and Wolfgang Wurst ${ }^{1,2,4,6}$ \\ ${ }^{1}$ Max-Planck-Institut für Psychiatrie, D-80804 Munich, Germany, ${ }^{2}$ Institute of Developmental Genetics and ${ }^{3}$ Institute of Experimental Genetics, Helmholtz \\ Zentrum München, D-85764 Neuherberg, Germany, ${ }^{4}$ Lehrstuhl für Entwicklungsgenetik, ${ }^{5}$ Lehrstuhl für Experimentelle Genetik, Technische Universität \\ München, D-85350 Freising-Weihenstephan, Germany, and ${ }^{6}$ Deutsches Zentrum für Neurodegenerative Erkrankungen, München, \\ D-80336 Munich, Germany
}

Urocortin 3 (UCN3) is strongly expressed in specific nuclei of the rodent brain, at sites distinct from those expressing urocortin 1 and urocortin 2, the other endogenous ligands of corticotropin-releasing hormone receptor type 2 (CRH-R2). To determine the physiological role of UCN3, we generated UCN3-deficient mice, in which the UCN3 open reading frame was replaced by a tau-lacZ reporter gene. By means of this reporter gene, the nucleus parabrachialis and the premammillary nucleus were identified as previously unknown sites of UCN3 expression. Additionally, the introduced reporter gene enabled the visualization of axonal projections of UCN3-expressing neurons from the superior paraolivary nucleus to the inferior colliculus and from the posterodorsal part of the medial amygdala to the principal nucleus of the bed nucleus of the stria terminalis, respectively. The examination of tau-lacZ reporter gene activity throughout the brain underscored a predominant expression of UCN3 in nuclei functionally connected to the accessory olfactory system. Male and female mice were comprehensively phenotyped but none of the applied tests provided indications for a role of UCN3 in the context of hypothalamic-pituitary-adrenocortical axis regulation, anxiety- or depression-related behavior. However, inspired by the prevalent expression throughout the accessory olfactory system, we identified alterations in social discrimination abilities of male and female UCN3 knock-out mice that were also present in male CRH-R2 knock-out mice. In conclusion, our results suggest a novel role for UCN3 and CRH-R2 related to the processing of social cues and to the establishment of social memories.

\section{Introduction}

Urocortin 3 (UCN3) and its closest relative urocortin 2 (UCN2), which are also known as stresscopin and stresscopin-related peptide, respectively, are the most recently discovered members of the corticotropin-releasing hormone (CRH) family of neuropeptides (Hsu and Hsueh, 2001; Lewis et al., 2001; Reyes et al., 2001). UCN3, together with UCN2, are exclusive ligands of CRH receptor type 2(CRH-R2); their affinity toward CRH receptor type 1 (CRH-R1) is negligible (Hsu and Hsueh, 2001; Lewis et al., 2001). $\mathrm{UCN} 3$ and $\mathrm{UCN} 2$ are paralogs of CRH and urocortin (UCN) and define a separate phylogenetic branch, suggesting that these genes

Received March 1, 2010; revised May 5, 2010; accepted May 11, 2010.

This work was partially supported by the Bundesministerium für Bildung und Forschung within the framework of the Nationales Genomforschungsnetz Plus (FKZ: 01GS0850, 01GS08151, and 01GS08155), the European Commission (EUMODIC: LSHG-2006-037188), by the Initiative and Networking Fund of the Helmholtz Association in the framework of the Helmholtz Alliance for Mental Health in an Ageing Society (HA-215), and by Fonds der Chemischen Industrie. We thank Katja Mayer, Tanja Orschmann, Daniela Kohl, Jessica Koepke, and Ursula Habersetzer for excellent technical assistance. We thank Susanne Bourier and Sawoula Michailidou for blastocyst injection and generation of chimeric mice. We thank K. R. Thomas, P. Soriano, and P. Mombaerts for gifts of plasmids PACN, pROSA26-1, and ETLPA-/LTNL, respectively. We also thank the members of the German Mouse Clinic for comprehensive phenotyping of the mice and fruitful discussions. Moreover, we thank Carola Hetzel and Katharine Webb for critical comments on this manuscript.

Correspondence should be addressed to Jan M. Deussing, Molecular Neurogenetics, Max Planck Institute of Psychiatry, Kraepelinstrasse 2-10, D-80804 Munich, Germany. E-mail: deussing@mpipsykl.mpg.de.

DOI:10.1523/JNEUROSCI.1049-10.2010

Copyright $\odot 2010$ the authors $\quad 0270-6474 / 10 / 309103-14 \$ 15.00 / 0$ emerged as early as the CRH/UCN branch. In rodents, UCN3 is expressed in distinct brain nuclei including the median preoptic nucleus (MPO), the rostral perifornical area of the hypothalamus (Pef), the medial amygdala (MeA), the bed nucleus of the stria terminalis (BNST), and the superior paraolivary nucleus (SPO) (Lewis et al., 2001). UCN3-immunoreactive fibers mostly overlap with sites that strongly express its cognate receptor CRH-R2 such as the MeA, the lateral septum (LS), the ventromedial nucleus of the hypothalamus (VMH), and the premammillary nucleus (PMV) (Li et al., 2002; Cavalcante et al., 2006). Based on this colocalization and its high affinity for CRH-R2, it is conceivable that UCN3 is the primary modulator of the impact of CRH-R2 on neuroendocrine and behavioral stress responses. Along these lines, UCN3 has been demonstrated to modulate stress-coping behavior (i.e., intracerebroventricular injection of $\mathrm{UCN} 3$ results in suppression of locomotor activity and anxiolytic-like effects as well as inhibition of food intake) (Valdez et al., 2003; Ohata and Shibasaki, 2004; Fekete et al., 2007). Moreover, centrally applied $\mathrm{UCN} 3$ is able to activate the hypothalamic-pituitary-adrenocortical (HPA) axis and thereby augments the neuroendocrine stress response. The expression of UCN3 itself in distinct brain nuclei is differentially regulated by stress and glucocorticoids (Jamieson et al., 2006). In peripheral organs, UCN3 has been detected in the gastrointestinal system (Lewis et al., 2001; Saruta et al., 2005). It is strongly expressed in pancreatic beta cells and is able to stimulate 
insulin and glucagon secretion (Li et al., 2003). Accordingly, recently generated knock-out mice confirmed that UCN3 is regulating glucose-stimulated insulin secretion and is critical for energy homeostasis (Li et al., 2007).

Despite these findings, our understanding of the physiological role of UCN3 in different brain nuclei remains mostly elusive. Therefore, we generated UCN3 mutant mice by substituting the $U c n 3$ gene with a tau-lacZ $(t Z)$ reporter gene (Mombaerts et al., 1996), which allowed us to monitor central and peripheral UCN3 expression. Assuming that UCN3, together with UCN2, is the major endogenous ligand of CRH-R2, we hypothesized that its disruption would interfere with anxiety-like behavior and stress adaptation as demonstrated for CRH-R2 mutant mice (Bale et al., 2000; Coste et al., 2000; Kishimoto et al., 2000; Bale and Vale, 2003). However, neither the neuroendocrine characterization nor any of the procedures used for behavioral phenotyping provided evidence for a role of UCN3 in HPA axis regulation, anxiety- or depression-related behavior under basal conditions. Instead, we have demonstrated a role for UCN3 and its cognate receptor $\mathrm{CRH}-\mathrm{R} 2$ in behaviors related to social memory.

\section{Materials and Methods}

Generation of Ucn3 knock-out mice. To generate a vector for targeting $\mathrm{UCN} 3$, we used the loxP flanked $t A C E-C r e / \mathrm{Neo}^{r}$ (ACN) cassette as selfexcising selection marker (Bunting et al., 1999). This cassette was cut with BglII from pACN and introduced into the BamHI site of pBluescript $\mathrm{KS}+$. In addition, a partial tau-LacZ reporter gene ( $\mathrm{N}$ terminus missing) was isolated from ETLpA-/LTNL (Mombaerts et al., 1996) and inserted into the NotI/XbaI sites of the previous construct in reverse orientation in relation to the ACN cassette. The bovine growth hormone polyadenylation sequence (bGH pA) was inserted into the $\mathrm{XbaI}$ site downstream of tau-lacZ. The bGH pA was subcloned from pSA $\beta$ geo (Friedrich and Soriano, 1991). The construct was further modified by introducing linker A (5'-CTC-GAG-AGG-CCT-CTT-AAG-AAT-GCT-GTA-CAGCTA-GCG-GTA-CC- $3^{\prime}$ ) into the XhoI/KpnI sites upstream of the ACN cassette and linker B (5'-GGC-CGT-CGA-CGT-TTA-AAC-AGA-TCTTAA-TTA-ATG-AAT-TCG-CGG-CCG-C-3') into the NotI site upstream of Tau-LacZ. To complete the shuttle vector, a diphtheria toxin A (DTA) expression cassette was isolated by SalI/XhoI from pROSA26-1 (Soriano, 1999) and introduced into the SalI site within linker A in reverse orientation in relation to the Tau-LacZ reporter gene.

For generation of homology arms (HAs), the 129/ola mouse cosmid library (library no. 121; Resource Center of the German Human Genome Project) was screened using a full-length murine Ucn 3 cDNA probe. The clone MPMGc121C18709Q2, which was confirmed by Southern blotting and sequencing as containing the entire $U c n 3$, was used as template for subsequent PCR amplification of HAs using the Expand Long Template PCR System (Roche). The $2 \mathrm{~kb} 3^{\prime}$-HA was amplified with primers MSC224Xho, 5' -CTC-GAG-CTT-TAA-CTC-TAT-TGA-GAA-3', and MSC225Nhe, 5'-GCT-AGC-TTG-AGA-TGT-CTT-CAT-TCA-A-3', subcloned into pCRII-TOPO using the TOPO TA cloning kit (Invitrogen), and sequenced (Sequiserve). The sequence-verified $3^{\prime}$-HA was inserted into the shuttle vector via XhoI/NheI. The $5^{\prime}$-HA was amplified in two parts. The $5^{\prime}$ part was amplified with primers MSC2-12Sal, 5'-GTCGAC-AGT-GAC-ACA-CTA-CAA-CTC-CC-3', and MSC2-8, 5'-GGCATC-AGC-ATC-GCT-CCC-3' , and subcloned into pCRII-TOPO. The $3^{\prime}$ part of the $5^{\prime}$-HA was obtained by overlapping PCR of two PCR products. The first PCR product was amplified with primers MSC2-18, 5'-AAA-CAA-GCT-AGA-AAT-GCC-AGA-C-3', and MSC2-ATGnc, 5'-CCT-GGC-GGG-GCT-CAG-CCA-TCA-GCA-TCG-CTC-CCT-GT-3', from MPMGc121C18709Q2; the second product with primers MSC2ATGc, 5'-ACA-GGG-AGC-GAT-GCT-GAT-GGC-TGA-GCC-CCGCCA-G-3', and MSC2-Tau, 5'-CTT-GGT-CTT-CCA-GGT-TGG-AC-3', from ETLpA-/LTNL (Mombaerts et al., 1996). The overlapping product was amplified with primers MSC2-18 and MSC2-Tau, subcloned into pCRII-TOPO, and sequenced. The $3^{\prime}$ part of the $5^{\prime}$-HA was inserted into the pCRII-TOPO construct containing the $5^{\prime}$ part via BsmI/NotI. The completed $5.5 \mathrm{~kb} \mathrm{5'-HA,} \mathrm{resulting} \mathrm{in} \mathrm{a} \mathrm{substitution} \mathrm{of} \mathrm{the} \mathrm{entire} U_{c n} 3$ open reading frame (ORF) by the Tau-LacZ reporter gene, was inserted into the shuttle vector via BglII/NotI.

External probes, used for identification of homologous recombination events, were amplified by PCR from genomic DNA and cloned into pCRII-TOPO: probe A, forward, $5^{\prime}$-TCC-TGG-TTC-CAA-GTT-AAACC-3', and reverse, 5'-ATA-GAC-CTG-GGT-GGT-ATG-G-3' ${ }^{\prime}$ (526 bp); probe B, forward, $5^{\prime}$-TCT-CTT-TGA-ACC-CAC-ATA-CC- ${ }^{\prime}$, and reverse, 5'-GGC-AGC-ATT-GAC-TTC-TTT-CC-3' (155 bp).

The linearized (via BglII) targeting vector, bearing $7.5 \mathrm{~kb}$ homology to the murine $U c n 3$ locus, was electroporated into embryonic day $14 \mathrm{em}-$ bryonic stem (ES) cells (129P2/OlaHsd). Mutant ES cell clones were identified by Southern blot analysis of genomic ES cell DNA digested with HpaI or EcoRI using the external probes A and B, respectively. Mutant ES cells were used to generate chimeric mice by blastocyst injection. Germ line transmission of the modified Ucn3 allele and selfexcision of the selection marker was confirmed in offspring from male chimeras bred to wild-type C57BL/6J mice. Genotyping was performed by PCR using the following primers: ESCP-GT1, 5'-TGT-CCT-CCTCAG-ACC-GAA-GT-3', ESCP-GT2A, 5'-AAT-TCT-TGG-CCT-TGTCGA-TG-3' , and ESCP-GT3, 5' -ATC-CAC-TAA-GGG-TGC-TGT-CG-3'. Standard PCR conditions resulted in a 503 bp wild-type and a 283 bp mutant PCR product. Mice used for this study were backcrossed to C57BL/6J for seven generations.

Generation of Ucn 2 knock-out mice. The HAs were generated by screening the 129/ola mouse cosmid library (library no. 121; Resource Center of the German Human Genome Project) using a full-length murine Ucn2 cDNA probe. The clone MPMGc121J20123Q2, which was confirmed by Southern blotting and sequencing as containing the entire Ucn2 locus, was used as template for subsequent PCR amplification of HAs using the Expand Long Template PCR System (Roche). The $3 \mathrm{~kb} 3^{\prime}$-HA was amplified with the primer $5^{\prime}$-TTA-CTC-AGA-TAT-GAA-CTT-GGC-3' and $5^{\prime}$-CAA-ATA-CTA-GCC-CAT-GTT-GG-3', subcloned into pCRIITOPO using the TOPO TA cloning kit (Invitrogen), and sequenced (Sequiserve). The verified sequence was inserted into the shuttle vector (see above) via Asp7 18/XhoI. The 5' -HA was obtained by overlapping PCR of two PCR products. The first PCR product was amplified with the primer MUc6, 5'-GTA-GAA-GCA-GTA-ACA-GAT-GC-3', and MUc-ATGtau-1, 5'-GGG-CTC-AGC-CAT-CAT-GTG-GGA-AGG-CTG-TAA-G-3'; the second product was generated by MUc-ATG-tau-2, 5' -CCT-TCCCAC-ATG-ATG-CTG-AGC-CCC-GCC-A- $3^{\prime}$, and tau-2, $5^{\prime}$-CCT-TGGTTT-TTT-TGT-CAT-CGG-3' from ETLpA-/LTNL. The overlapping product was amplified with MUc6-Pac, 5' -TTA-ATT-AAG-TAG-AAGCAG-TAA-CAG-ATG-C-3', and tau-2, subcloned into pCRII-TOPO, and sequenced. The completed $5^{\prime}$-HA was inserted into the shuttle vector via PacI/NotI. The targeting vector resulted in a substitution of the entire open reading frame located in exon 2 of $U c n 2$ by the tau-LacZ reporter gene.

External probes used for identification of homologous recombination events were amplified by PCR from genomic DNA and cloned using the TOPO TA cloning kit (Invitrogen): probe A, forward, 5' -TAA-GGTATA-GAT-GTA-ACA-ATG-G-3' , and reverse, $5^{\prime}$-TGT-TGT-CTACCT-TTT-CAT-GC-3' (621 bp); probe B, forward, 5' -AAT-TGG-TACACT-TTG-AGA-TGC-3', and reverse, 5'-GTG-AAC-TCC-TTT-TCTGAA-GC-3' (566 bp).

The linearized (via PacI) targeting vector bearing $7.5 \mathrm{~kb}$ homology to the murine Ucn2 locus was electroporated into TBV2 ES cells (129S2). Mutant ES cell clones were identified by Southern blot analysis of genomic ES cell DNA digested with SacI or HindIII using the external probes A and B, respectively. Mutant ES cells were used to generate chimeric mice by blastocyst injection. Germ line transmission of the modified Ucn2 allele and self-excision of the selection marker was confirmed in offspring from male chimeras bred to wild-type C57BL/6J mice. Genotyping was performed by PCR using the following primers: SRP-MR3, 5'-TCC-TCC-AGA-ACT-TCT-CAT-CCA-3'; SRP40, 5' CGT-GGC-CTC-TGT-AAC-CTC-TC-3'; and TAU-REV2, 5'-GTCTTC-CAG-GTT-GGA-CGT-GT-3'. Standard PCR conditions resulted in a 521 bp wild-type and a 465 bp mutant PCR product. Mice used for this study were backcrossed to C57BL/6J for seven generations. 
In situ hybridization. Ten-week-old mice were killed in the morning (10:00 A.M.) using an overdose of isoflurane. Brains were carefully removed and immediately shock frozen on dry ice. Frozen brains were cut on a cryostat in $20-\mu \mathrm{m}$-thick sections. For quantitative in situ hybridization, cryostat sections of $U_{c n} 3^{+/+}$and $U c n 3^{t Z / t Z}$ brains were mounted side by side on SuperFrost Plus slides (Menzel). This procedure allowed for parallel in situ hybridization of sections under identical conditions assuring meaningful quantification and comparison of hybridization signals. All sections were processed for in situ hybridization as previously described (Deussing et al., 2007). The riboprobe for UCN3 covered nucleotides 505-1136 of GenBank accession number NM_031250 and was generated by PCR, labeled, and hybridized as previously described (Deussing et al., 2007). The hybridized slides were dipped in autoradiographic emulsion (type NTB2; Eastman Kodak), developed after 3-6 weeks, and counterstained with cresyl violet.

$X$-Gal staining. Two- to 3 -month-old mice ( $n=4-5$ per genotype) were killed using an overdose of isoflurane and transcardially perfused with $4 \%$ paraformaldehyde, $1 \mathrm{~mm} \mathrm{MgCl}_{2}$, and $5 \mathrm{~mm}$ EGTA. Subsequent $\mathrm{X}-\mathrm{Gal}$ staining was performed on free-floating 50 - or $200-\mu \mathrm{m}$-thick vibratome sections or on intact organs as previously described (Mombaerts et al., 1996). For clearing, vibratome sections or brains were dehydrated through an $\mathrm{EtOH} / \mathrm{H}_{2} \mathrm{O}$ series to $100 \%$ alcohol. Sections were incubated 20 min in 1:2 BABB (1:2 benzyl alcohol to benzyl benzoate) to alcohol, 20 min in 2:1 BABB to alcohol, and finally transferred to BABB. Photomicrographs were taken using a binocular microscope after the clearing process had been accomplished.

Endocrine analyses. Two weeks before the experiments, 3- to 5-monthold mice were separated and individually housed with a $12 \mathrm{~h} \mathrm{light/dark}$ schedule (lights off at 7:00 P.M.). To determine the basal corticosterone plasma levels, mice were left undisturbed throughout the night before the experiment. Blood sampling was performed in the early morning (7:309:30 A.M.) and afternoon (4:30-5:30 P.M.) by collecting trunk blood from mice rapidly decapitated under light isoflurane anesthesia or by incision of the tail, with the time from first handling of the mouse to completion of bleeding not exceeding $45 \mathrm{~s}$. For evaluation of the endocrine response to stress, we collected blood samples immediately after 2, 5, and $10 \mathrm{~min}$ of restraint stress or 30,60, and 90 min after 10 min restraint stress, for which mice were placed in a $50 \mathrm{ml}$ conical tube with the bottom removed. Stress experiments were performed in the morning (7:30-10:00 A.M.). Plasma corticosterone concentrations were measured in duplicate using a commercially available RIA kit (MP Biomedicals).

Mice for behavioral testing. A primary phenotype screen was performed according to the standard workflow of the German Mouse Clinic (GMC) (http://www.mouseclinic.de) (Gailus-Durner et al., 2005, 2009). All experiments were performed testing $U c n 3^{t Z / t Z}$ and $U c n 3^{+/+}$littermate controls concurrently. In total, $84 U c n 3^{+/+}$(41 females; 43 males) and $81 \mathrm{Ucn}^{t Z / t Z}$ mice (42 females; 39 males) were used for behavioral analysis in three batches of similar sizes ( $n=10-16$ per group) at the GMC. Additional results will be available on the EuroPhenome web page (http://www.europhenome.org).

Elevated plus maze. The test arena was made of light gray PVC [poly(vinyl chloride)] and consisted of two open arms $(30 \times 5 \times 0.3 \mathrm{~cm})$ and two closed arms of the same size with $15-\mathrm{cm}$-high walls. The open arms and, accordingly, the closed arms were facing each other, connected via a central square $(5 \times 5 \mathrm{~cm})$. The apparatus was elevated $75 \mathrm{~cm}$ above the floor by a pole fixed underneath the central square. The illumination level was set at $\sim 100$ lux in the center of the maze. For testing, each mouse was placed at the end of a closed arm (distal to the center) facing the wall and was allowed to explore the maze for $5 \mathrm{~min}$. A camera was mounted above the center of the maze to video monitor each trial by a trained observer in an adjacent room. The number of entries into each type of arm (placement of all four paws into an arm defined an entry), latency to enter the open arms, as well as the time spent in the open and closed arms were recorded by a trained observer with a hand-held computer using the Observer 4.1 software (Noldus). After each trial, the test arena was carefully cleaned with a disinfectant.

Social interaction. On 2 subsequent days before testing, mice were habituated separately to the testing arena (type II Macrolon cage; floor covered with bedding) for $10 \mathrm{~min}$ in moderate lighting conditions (40 lux) to enhance active interaction during testing (File and Hyde, 1978). For testing, two unfamiliar, weight-matched mice of the same sex and genotype were placed for into the known test area (40 lux) for $10 \mathrm{~min}$. The total time spent in active (grooming, sniffing at the partner, crawling under and over) and passive social behavior (sitting next to each other in physical contact) was recorded by a trained observer. Since social interaction time of an individual depends on the partners' social activity (Tõnissaar et al., 2004), the social interaction time was expressed nesting over the two partners.

Forced-swim test. The procedure was adapted from that of Ebner et al. (2002). In brief, the forced-swimming apparatus consisted of a cylindrical 10 L glass tank $(24.5 \mathrm{~cm}$ in diameter) filled with water to a depth of 20 $\mathrm{cm}\left(25 \pm 1^{\circ} \mathrm{C}\right)$. A trained observer recorded the mice behavior in moderate lighting conditions ( $\sim 30$ lux) for 6 min with a hand-held computer scoring the following behaviors: (1) struggling, defined as movements during which the forelimbs broke the water surface; (2) swimming, defined as movement of the mouse induced by movements of the forelimbs and hindlimbs without breaking the water surface; and (3) floating, defined as the behavior during which the mouse used limb movements just to keep its balance without any movement of the trunk. Data were analyzed using Observer 4.1 software (Noldus). After each trial, the mouse was dried with a tissue and put into a new cage, and the water was renewed before testing was continued.

Acoustic startle and prepulse inhibition. The startle apparatus and software ("Advanced Startle") from MED Associates (Startle Stimulus Package PHM-255A; ANL-925C Amplifier) was used. Acoustic startle response (ASR) and prepulse inhibition (PPI) were assessed during the same session, and experiments were performed between 8:30 A.M. and 5:00 P.M. Background noise was $65 \mathrm{~dB}$, and startle pulses were bursts of white noise $(40 \mathrm{~ms})$. A session was initiated by a $5 \mathrm{~min}$ acclimation period followed by five presentations of leader startle pulses $(110 \mathrm{~dB})$ that were excluded from statistical analysis. Trial types included seven different startle stimulus intensities $(70,80,85,90,100,110,120 \mathrm{~dB})$ and one NS (no stimulus) trial, in which only the background noise was present to determine baseline movement of the mouse. Startle response was measured as the first peak-to-peak response, with a minimum peak value of 50 arbitrary units occurring with a minimum wave onset latency of $20 \mathrm{~ms}$ and a minimum peak time of $30 \mathrm{~ms}$ after the onset of the startle stimulus.

A $12 \mathrm{kHz}$ pure tone of $10 \mathrm{~ms}$ duration was used as prepulse. Trial types for the PPI included four different prepulse intensities $(67,69,73,81 \mathrm{~dB})$, with each prepulse preceding the startle pulse $(110 \mathrm{~dB})$ by a $50 \mathrm{~ms}$ interstimulus interval. Each trial type for ASR and PPI was presented 10 times in random order, organized in 10 blocks, with each trial type occurring once per block. Intertrial intervals varied from 20 to $30 \mathrm{~s}$. This protocol is based on the Eumorphia protocol (see www.eumorphia.org), adapted to the specifications of our startle equipment (MED Associates).

Social discrimination. The social discrimination test was originally developed by Engelmann et al. (1995) to investigate olfactory-based learning and short-term memory processes in adult rats in a social context. Several modifications were made to further standardize and adapt the protocol for mice.

For each social discrimination test, both adult group-housed male mice were singly habituated to the experimental cages (Plexiglas $38 \times$ $22 \times 35 \mathrm{~cm}$ ) for $1 \mathrm{~h}$. Afterward, each experimental mouse was presented with an ovariectomized female stimulus mouse, fixed in a perforated plastic tube, for $5 \mathrm{~min}$. After interexposure intervals of 2, 4, or $6 \mathrm{~h}$, respectively, the first mouse (familiar) was reintroduced for $5 \mathrm{~min}$ to the male test mouse together with a second (unfamiliar) stimulus mouse (also in a plastic tube). Each experimental mouse underwent the four different interexposure intervals (on different experimental days) with a consequent change in stimulus mice per run (i.e., each mouse was presented with new stimulus females during each trial). All experiments were performed between 8:00 A.M. and 3:00 P.M. and videotaped for later analysis. The duration of olfactory investigation toward the respective stimulus mouse in both sessions was quantified by an observer blind to the genotype using the computer software Eventlog (Event Recorder 1.0; R. Henderson, Germany, 1986). 
The total investigation time during the first exposure was quantified to exclude nonspecific effects. According to Engelmann et al. (1995), a significantly increased olfactory investigation of the unfamiliar stimulus female during the second exposure was taken as parameter for the animals' social discrimination ability.

Social odor perception. Again, in this testing procedure, mice were first habituated separately to the testing arena (type II Macrolon cage without bedding) for $10 \mathrm{~min}$ in moderate lighting conditions on 2 subsequent days before testing. On the test day, mice were exposed to a discriminatory odor perception task. For testing, two Eppendorf tubes were inserted upside down in a type II Macrolon cage with predrilled holes to hold the tubes, with each tube centered in one-half of the cage. One tube was filled with clean bedding (neutral stimulus), the other one with heavily soiled bedding of sexually mature C57BL/6J mice of the same sex (social stimulus). The tip of the tubes were cut just before testing. Each experimental mouse was allowed to explore the testing arena individually for $10 \mathrm{~min}$, during which a trained observer recorded the latency, frequency, and duration of exploration of the tip of the tubes (sniffing) with a hand-held computer. Data were analyzed using Observer 4.1 software (Noldus). After each trial, the test arena was carefully cleaned with a disinfectant. Fresh tubes were used for each mouse, and the position of the tubes was counterbalanced across the experiment.

Olfactory test battery. Homozygous $U c n 3^{t Z I t Z}$ mutant mice and wildtype littermates $(n=12 / 11)$ were tested in a "simultaneous smell discrimination task" to detect graded differences in their olfactory abilities. The procedure was adapted from that of Mihalick et al. (2000). For the conditioning procedure, mice were placed on a restricted feeding regimen to maintain their body weight at $\sim 90 \%$ body weight of their freefeeding level for the duration of training and testing. Experimental sessions were conducted $5 \mathrm{~d}$ per week, one session with 12-18 trials per day. The testing was conducted using standard mouse cages $(18.5 \mathrm{~cm}$ wide, $29.5 \mathrm{~cm}$ long, $13 \mathrm{~cm}$ high), and a small amount of bedding was placed at the far end of the cage. Odorants were presented on fresh bedding shavings (ratio: $1 \mathrm{ml}$ per $3 \mathrm{~g}$ shavings) in two circular, plastic dishes $(3 \mathrm{~cm}$ diameter) that were mounted horizontally on a carrier, separated by a vertical barrier between them. For each trial, the carrier was inserted in the front part of the test cage. Between trials, the mouse was separated from the front part by a barrier inserted by the experimenter. During pretraining trials, a single dish was presented equally often in the left or right location. First, mice were trained for $3 \mathrm{~d}$ to dig in the dish filled with clean, unscented bedding shavings to retrieve a small piece of chocolate. For the discrimination tasks, two identical dishes were presented simultaneously. In the simple condition, one dish was scented with the odorant phenethylacetate (Sigma-Aldrich; smelling of apple; diluted to a concentration of $10 \%$ ) that was designated $[\mathrm{S}+]$ and the other with the same amount of solvent (diethyl phthalate; SigmaAldrich). On the first day, digging in the dish scented with $[\mathrm{S}+]$ was consistently rewarded with chocolate for up to 18 successful trials. To train the mice to associate $[\mathrm{S}+]$ smell and not the chocolate with the reward, on the second day the chocolate was buried in both dishes but mice were only allowed to dig in $[\mathrm{S}+]$. Training was completed after 18 successful trials. On the following $2 \mathrm{~d}$, the mice had to discriminate between $[\mathrm{S}+]$ and another odorant methyl trans-cinnamate (Sigma-Aldrich; diluted to a concentration of $10 \%$; smelling like strawberry) that was designated $[\mathrm{S}-$ ]. A correct choice was defined as digging first in the dish with $[\mathrm{S}+]$ scented shavings. Number of errors (digs) in the unrewarded dish, and the dish of first choice (choice accuracy in percentage) were recorded. In a more difficult procedure, the mice had afterward to discriminate between different binary mixtures of $[S+]$ and $[S-]$ to make the odorants more similar $([\mathrm{S}+]:[\mathrm{S}-]$ vs $[\mathrm{S}+]:[\mathrm{S}-], 70: 30$ vs 30 : $70 ; 55: 45$ vs $45: 55 ; 53: 47$ vs $47: 53 ; 51: 49$ vs $49: 51 ; 50: 50$ vs $50: 50)$. A correct choice was defined as digging first in the dish with the higher amount of $[\mathrm{S}+]$, and this was followed by the delivery of a small piece of chocolate by the experimenter with forceps. In a failed discrimination, in which the mice chose the $[S-]$ rather than the $[S+]$, both dishes were immediately removed from the cage, terminating the trial. One concentration was tested per day in 18 trials.

For the smell sensitivity test, mice were tested in binary steps of dilution, starting from a concentration of $10 \%$. Mice had to discriminate between a dish scented with [S+] and another dish with just the solvent. If a mouse responded correctly, it was tested on the next, lower dilution binary step (three trials per each concentration step; three to six steps per day). If the mouse responded incorrectly, it was retested with the previous, stronger, binary step to determine the threshold.

Object recognition. An object recognition procedure with three $5 \mathrm{~min}$ sample trials (intertrial interval, $15 \mathrm{~min}$ ), and two test trials 3 and $24 \mathrm{~h}$ after the end of the third sample trial were performed as previously described (Feil et al., 2009; Pham et al., 2009). Significantly longer investigation durations of the novel object compared with the familiar one was taken as an evidence for an intact recognition memory. In addition, a recognition index was calculated as follows: index $=$ investigation time novel/(investigation time familiar + investigation time novel). All data were analyzed by using the Observer 4.1 software (Noldus).

Fear conditioning. All experimental procedures were approved by the Committee on Animal Health and Care of the local governmental body (i.e., Regierung von Oberbayern) and performed in strict compliance with the guidelines for the care and use of laboratory animals set by the European Community (86/609/CEE).

The experimental procedures and the equipment used for fear conditioning were previously described in detail (Kamprath and Wotjak, 2004). For auditory fear conditioning (i.e., background contextual conditioning), mice were placed into the conditioning chamber and the house light (10 lux) was switched on. After a habituation phase of $3 \mathrm{~min}$, a sine wave tone $(80 \mathrm{~dB} ; 9 \mathrm{kHz})$ was presented for $20 \mathrm{~s}$ [conditioned stimulus $(\mathrm{CS}+)]$ that coterminated with a $2 \mathrm{~s}$, scrambled electric footshock [unconditioned stimulus (US)] of $0.70 \mathrm{~mA}$. Mice remained in the conditioning chamber for additional $60 \mathrm{~s}$ before they were returned to their home cages. After each trial, the chamber was thoroughly cleaned with $70 \%$ ethanol, and the bedding (wood shavings) placed underneath the grid was changed.

The intensity of contextual fear memory was assessed $24 \mathrm{~h}$ later by placing the mice back to the conditioning chamber for $3 \mathrm{~min}$. The specificity of contextual fear memory was assessed by placing the mice for 3 min into a novel context (hexagonal prism), which contained with the grid floor a dominant reminder of the conditioning chamber, and into a completely neutral context (cylinder) with interexposure intervals of $2 \mathrm{~h}$ (Golub et al., 2009). For measuring auditory-cued fear memory, mice were exposed to a 3 min tone $(80 \mathrm{~dB} ; 9 \mathrm{kHz})$ in the cylinder after the $3 \mathrm{~min}$ baseline period. The latter procedure was repeated another $5 \mathrm{~d}$ later for measuring extinction of auditory-cued fear memory.

Animals' behavior was videotaped for subsequent off-line analysis. Freezing (i.e., the absence of all movements except for respiration) served as a measure of fear memory. Freezing was scored by a trained observer by means of customized freeware software (EVENTLOG) unaware of the genotype. Data were normalized to the total observation periods of $3 \mathrm{~min}$ and analyzed by two-way ANOVAs (genotype by context or genotype by day) for repeated measurements (context or day) as indicated in the text.

Statistical analysis. The SPSS software (SPSS) was used for statistical analyses. Data were analyzed for normal distribution, and parametric tests were used for normally distributed data, and nonparametric statistics were applied when the criteria for normal distribution were not met. Data were analyzed by one- or two-way ANOVAs for repeated measures where appropriate. For two-group comparisons, unpaired Student's $t$ test was used. For the social discrimination data, the nonparametric Wilcoxon test was applied, comparing the dependent data sets (first vs second exposure). For the olfactory discrimination and the smell sensitivity tests, the nonparametric Mann-Whitney test was applied. The chosen level of significance was $p<0.05$. To account for body weight differences, startle amplitude data were analyzed by two-way ANOVA with genotype as fixed factor, decibels as repeated measure, and body weight as covariant.

\section{Results}

\section{Generation of Ucn 3 mutant mice}

The targeting vector was designed to disrupt the Ucn3 gene and to replace the ORF by a tau-lac $Z(t Z)$ reporter gene (Fig. $1 A$ ). Targeting via homologous recombination resulted in the deletion of 
A

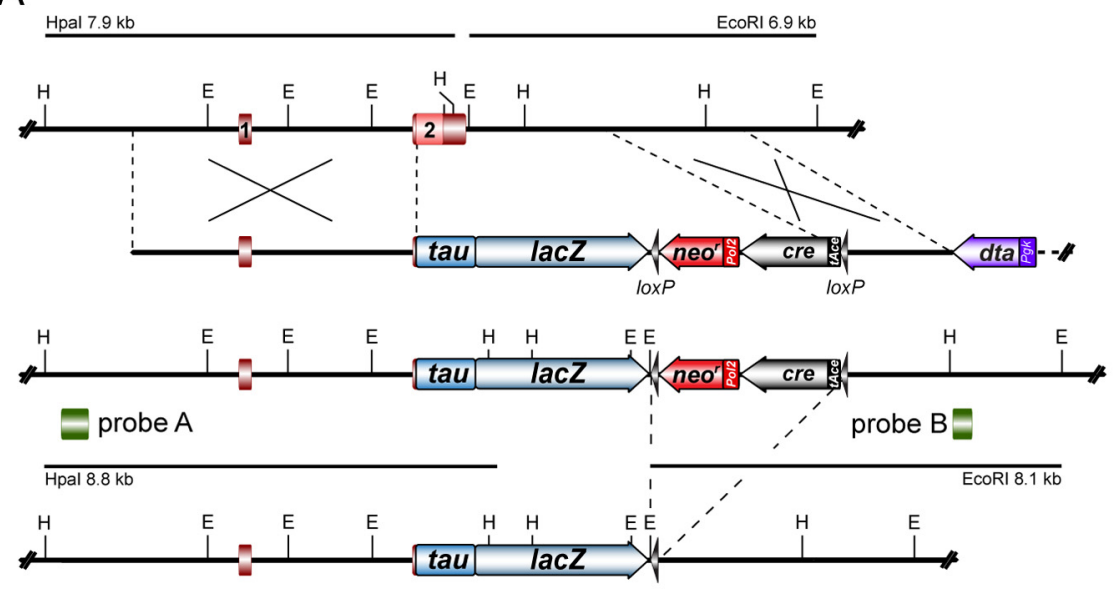

$1 \mathrm{~kb}$

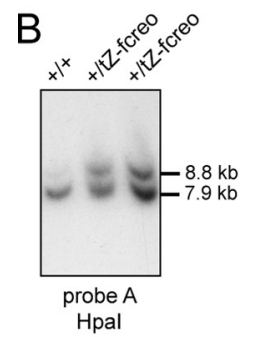

$\mathrm{F}$
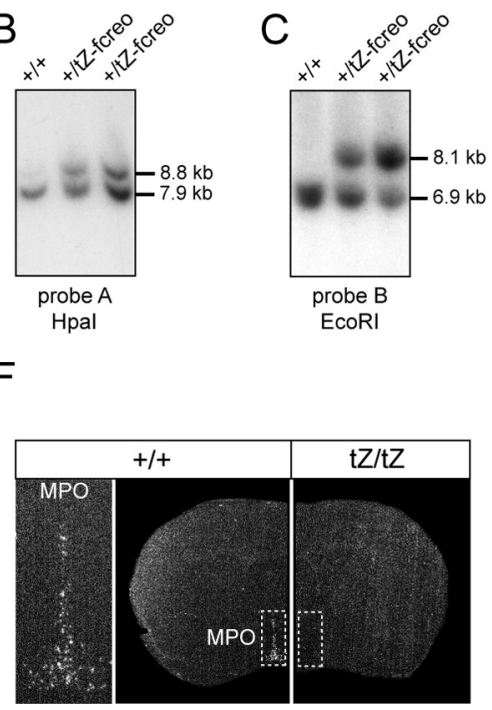

D

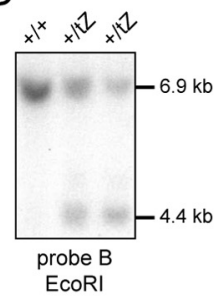

G

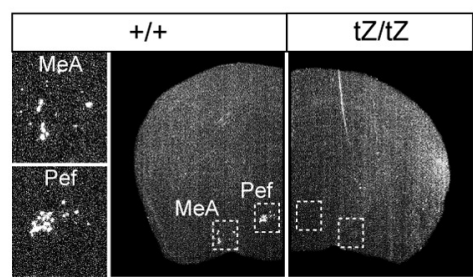

Figure 1. Generation of $U c n 3^{t Z}$ mice. $A$, Strategy for targeted disruption and substitution of $U c n 3$ by a tau-lacZ reporter gene (tZ). Partial restriction maps of wild-type $U c n 3$ locus, targeting vector, recombined $U c n 3^{t Z \text {-freo }}$ allele and $U c n^{t Z}$ allele after $c r e-$ mediated self-excision of the floxed cre-neo ( fcreo) cassette. E, EcoRl; H, Hpal; loxP sites are indicated as black arrowheads. $\boldsymbol{B}$, Southern blot analysis of wild-type and targeted ES cell clones. The Ucn3 $5^{\prime}$-probe A was hybridized to Hpal-digested genomic ES cell DNA. The targeted allele was indicated by the presence of an additional mutant $8.8 \mathrm{~kb}$ fragment. C, The Ucn3 $3{ }^{\prime}$-probe B was hybridized to EcoRI-digested DNA from the same ES cell clones, confirming homologous recombination by detection of an additional mutant fragment at $8.1 \mathrm{~kb}$. D, Southern blot analysis of EcoRl-digested tail DNA of $F_{1}$ progeny of germ line chimeras hybridized with the $3^{\prime}$-probe B. Self-excision of the fcreo cassette was indicated by the presence of an additional $4.4 \mathrm{~kb}$ fragment. $\boldsymbol{E}$, Genotyping of $\mathrm{F}_{2}$ mice through $P C R$ depicting wild-type, heterozygous, and homozygous $U \mathrm{cn} 3^{t Z}$ mice. $\boldsymbol{F}, \boldsymbol{G}$, The loss of $U \mathrm{cn} 3$ expression in $U c n 3^{t Z / t Z}$ mice was confirmed by radioactive in situ hybridization using a specific riboprobe for UCN3 exon 2 . Shown are representative dark-field photomicrographs of coronal sections of $U \mathrm{cn} 3^{+/+}$and $U \mathrm{cn} 3^{t z / t z}$ mice at the level of the MPO $(\boldsymbol{F})$ as well as at the level of the MeA and $\operatorname{Pef}(\boldsymbol{G})$.

a $3.6 \mathrm{~kb}$ segment of the $U c n 3$ gene. This segment comprises exon 2 , including the entire ORF as well as the untranslated and downstream regions of $U c n 3$ (Fig. $1 A-C$ ). In homologously recombined embryonic stem cells, the $t Z$ reporter gene is succeeded by a loxP flanked $t A C E-C r e / n e o{ }^{r}$ (ACN) cassette (tZ-fcreo, floxed cre neo) (Fig. $1 A-C$ ), which was successfully excised during germ line transmission of the modified Ucn 3 allele by breeding of male chimeric mice to C57BL/6J females (Fig. $1 D$ ). In the $\mathrm{F}_{2}$ generation, homozygous $U c n 3^{t Z / t Z}$ mutant mice were obtained at the expected Mendelian frequency (Fig. $1 E$ ).

To test for inactivation of the Ucn3 gene in homozygous mutant mice, its expression was studied by in situ hybridization on brain sections. No Ucn 3 transcript was detected throughout brains of $U c n 3^{t Z / t Z} \mathrm{mu}-$ tant mice, indicating that the $U c n 3$ gene was successfully disrupted (Fig. $1 F, G$ ). Homozygous UCN3-deficient mice exhibited normal development at birth and showed no obvious neurological or behavioral deficits. Postnatal development was indistinguishable from that of heterozygous and wild-type littermates. Inspection of external and internal organs at different ages did not reveal any macroscopic abnormalities and no pathological alterations were detected on histological investigation of various organ systems including brain, heart, lung, liver, spleen, thymus, pancreas, stomach, intestine, ovary, kidney, and skeletal muscle (data not shown). Homozygous mutant mice were fertile and reproduced normally.

\section{Tau-LacZ reporter gene activity in $U C N 3^{t Z}$ mice reflects the endogenous UCN3 expression pattern}

To examine $t Z$ reporter gene transcription from the Ucn3 locus, entire brains and sections were stained with X-Gal. Brains of heterozygous and homozygous Ucn3 mutant mice revealed intense blue staining of neurons within nuclei close to the ventral surface such as the MPO, Pef, MeA, and SPO (Fig. $2 A, B$ ). In the brain, we identified the PMV (Fig. $2 A-C$ ) and the nucleus parabrachialis (PB) (Fig. 2D) as previously unknown sites of Ucn3 expression. The PMV has been described as being innervated by UCN3-expressing neurons but lacks UCN3-positive somata (Cavalcante et al., 2006). We were not able to detect any Ucn 3 transcripts in the PMV, whereas expression in the murine $\mathrm{PB}$ was readily detected using in situ hybridization (Fig. 2J). The observed staining in the brain clearly reflects the expression pattern of endogenous Ucn 3 as previously determined by in situ hybridization (Lewis et al., 2001). We detected no difference between heterozygous and homozygous $U C N 3^{t Z}$ mice with respect to spatial distribution of the X-Gal staining.

In the periphery, strong $\mathrm{X}$-Gal staining was detected throughout pancreatic islets (Fig. $2 E, F$ ) as previously described (Li et al., 2003). Furthermore, and in accordance with Lewis et al. (2001), strong $t Z$ expression was detected in the small intestine (Fig. 2G-I), which was assigned to cells within intestinal crypts (Fig. $2 \mathrm{H}$ ) and to a subset of goblet cells of corresponding villi (Fig. 2I). In contrast to expression studies in humans (Hsu and Hsueh, 2001), careful inspection of other $\mathrm{X}$-Gal-stained peripheral organs, including the pituitary and adrenal gland, did not reveal any specific $t Z$ expression (data not shown). 
$L a c Z$ reporter gene activity reveals projections of the medial amygdala and the superior paraolivary nucleus

The genetic approach involving the tau$L a c Z$ reporter gene allowed us to monitor the axonal projections of UCN3-expressing neurons. Tau-LacZ is a histochemical marker, which is well transported down axons (Callahan and Thomas, 1994). Thorough analysis of X-Gal-stained $200 \mu \mathrm{m}$ vibratome sections of brains of heterozygous and homozygous $U C N 3^{t Z}$ mice revealed that $t Z / U c n 3$-expressing neurons in the MPO, Pef, PMV, BNST, and PB (Figs. 2, 3) have characteristics of locally projecting interneurons. X-Gal-stained neurons throughout the rostrocaudal extension of the MeA also have an interneuron-like appearance (Fig. 3). Additionally, we identified a population of neurons in the posterodorsal part of the MeA (MeApd) with long-distance projections (Fig. 3B-F,I-L). A bundle of axons originating in the MeApd initially ascends dorsally after the stria terminalis (ST) (Fig. $3 B, C, L$ ), and then turns rostrally remaining at the same horizontal level (Fig. $3 D, I-K)$ before the axons descend ventrally toward the midline after the postcommissural component of the ST (Fig. $3 E, F)$. Because of the fact that presynaptic terminals are not labeled by $t Z$ (as microtubules are excluded from nerve terminals), we can only hypothesize that these axons terminate in the posterior BNST, which has been described as a major target of MeApd projections (Dong et al., 2001) and which is a site of strong CRH-R2 expression in the brain (Van Pett et al., 2000).

We identified the SPO as another nucleus bearing long-distance projecting $t Z /$ $U c n 3$-positive neurons (Fig. 4A-G). These neurons send axons dorsocaudally, which then turn dorsally, ascend within the lateral lemniscus (LL) (Fig. $4 A, B, E, G$ ), and pass the UCN3-expressing PB (Fig. 4C,F) before they terminate in the inferior colliculus.

Together, these results demonstrate the usefulness of $U c n 3^{t Z}$ mice, which enabled the identification of the connectivities of UCN3-expressing neurons.

\section{Hypothalamic-pituitary-adrenal axis activity in $U c n 3^{t Z}$ mice is normal}

CRH-R2 is known to be involved in shaping HPA axis activity and its ligand UCN3 is expressed in brain sites relevant to HPA axis regulation. Therefore, we investigated the activity of the HPA axis in male and female $U c n 3^{+/+}$and $U c n 3^{t Z / t Z}$ mice. Under basal housing conditions, plasma corticosterone levels did not differ significantly between male $U c n 3^{+/+}$and $U c n 3^{t Z / t Z}$ littermates, neither at the diurnal trough, nor at the diurnal peak (Fig. 5). To examine the response of the HPA axis to stress, mice were subjected to 2, 5, and $10 \mathrm{~min}$ of restraint stress in the morning and
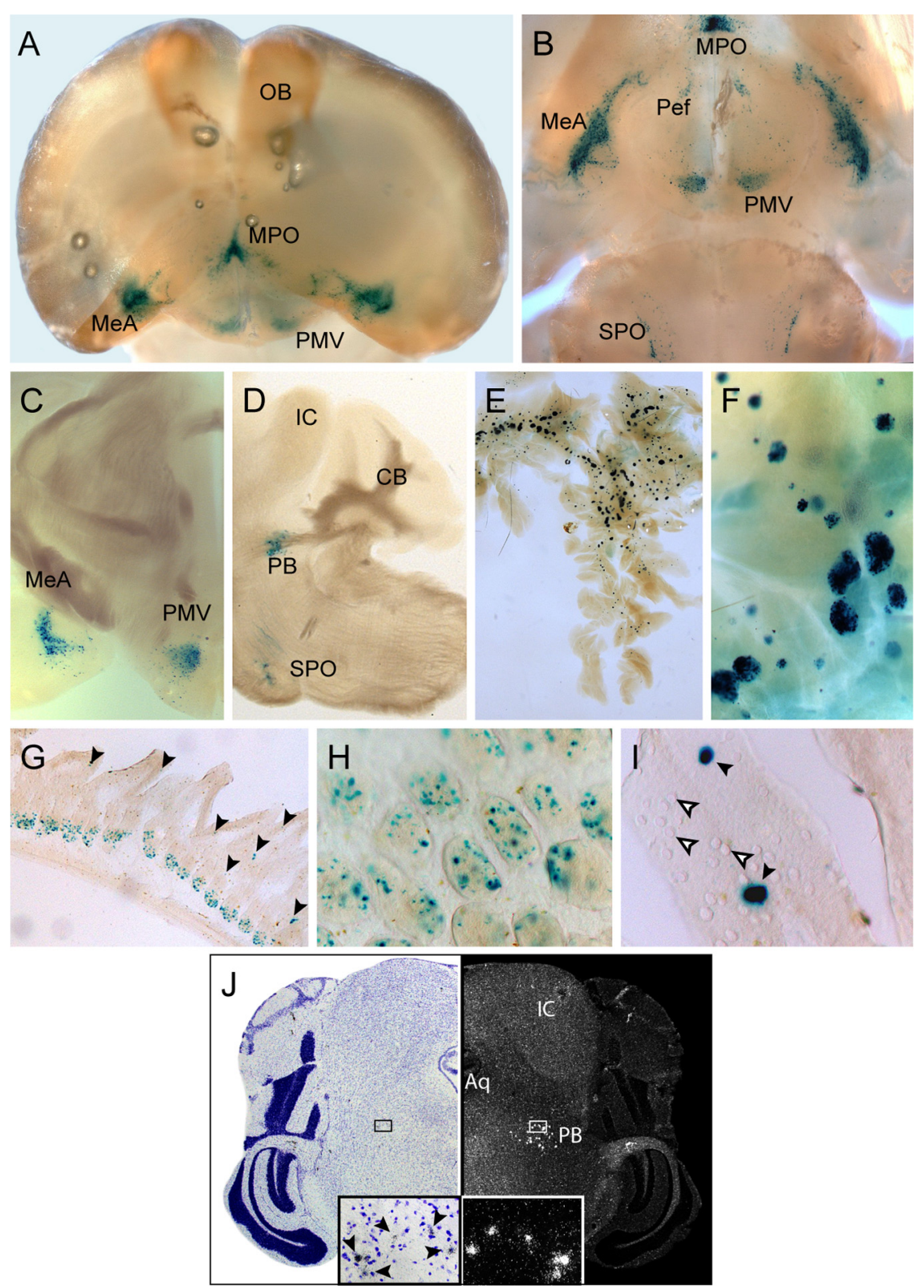

Figure 2. Expression of the tau-LacZ reporter gene introduced into the $U c n 3$ locus fully recapitulates the central and peripheral sites of UCN3 expression. $\boldsymbol{A}, \boldsymbol{B}$, Frontal $(\boldsymbol{A})$ and ventral $(\boldsymbol{B})$ whole-mount view of a X-Gal-stained brain of an $U \mathrm{Cn} 3^{+/ t z}$ mouse after $B A B B$ clearing. Strong staining was visible in the MPO, MeA, Pef, PMV, and SPO.C, Coronal section depicting strong tau-LacZ/UCN3expression in the MeA and PMV.D, Sagittal section depicting strong tau-LaCZ/UCN3 expression in the SPO and in the PB. E, F, X-Gal staining reflected strong UCN3 expression in Langerhans islets of the pancreas. G, Tau-LacZ reporter gene expression in the small intestine. $\boldsymbol{H}, \boldsymbol{I}$, Higher magnification of X-Gal staining of cells within $(\boldsymbol{H})$ intestinal crypts and in $(\boldsymbol{I})$ a subset of goblet cells as indicated by black arrowheads. Tau-LacZ-negative goblet cells are indicated by white arrowheads. $J$, In situ hybridization of a coronal mouse brain sections displaying UCN3 expression in the PB. A bright-field picture of a cresyl violet-stained section (left) and corresponding dark-field photomicrograph (right) are shown. Enlargements of the indicated small boxes displaying UCN3expressing cells within the PB are shown at the bottom. UCN3-positive cells in the bright-field enlargement are indicated by arrowheads. IC, Inferior colliculus; Aq, aqueduct.

killed directly afterward. Stress-induced elevation of corticosterone levels in male $U c n 3^{+/+}$and $U c n 3^{t Z / t Z}$ mice did not differ significantly (Fig. 5). Moreover, the negative-feedback regulation of the HPA axis, which was assessed 30, 60, and 90 min after the end of a 10 min restraint stress, was as efficient in knock-out mice as in their wild-type littermates (Fig. 5). Similar to males, female $U c n 3^{+1+}$ mice also showed no difference in basal or stressinduced corticosterone levels compared with their $U c n 3^{t Z / t Z}$ counterparts (data not shown). 

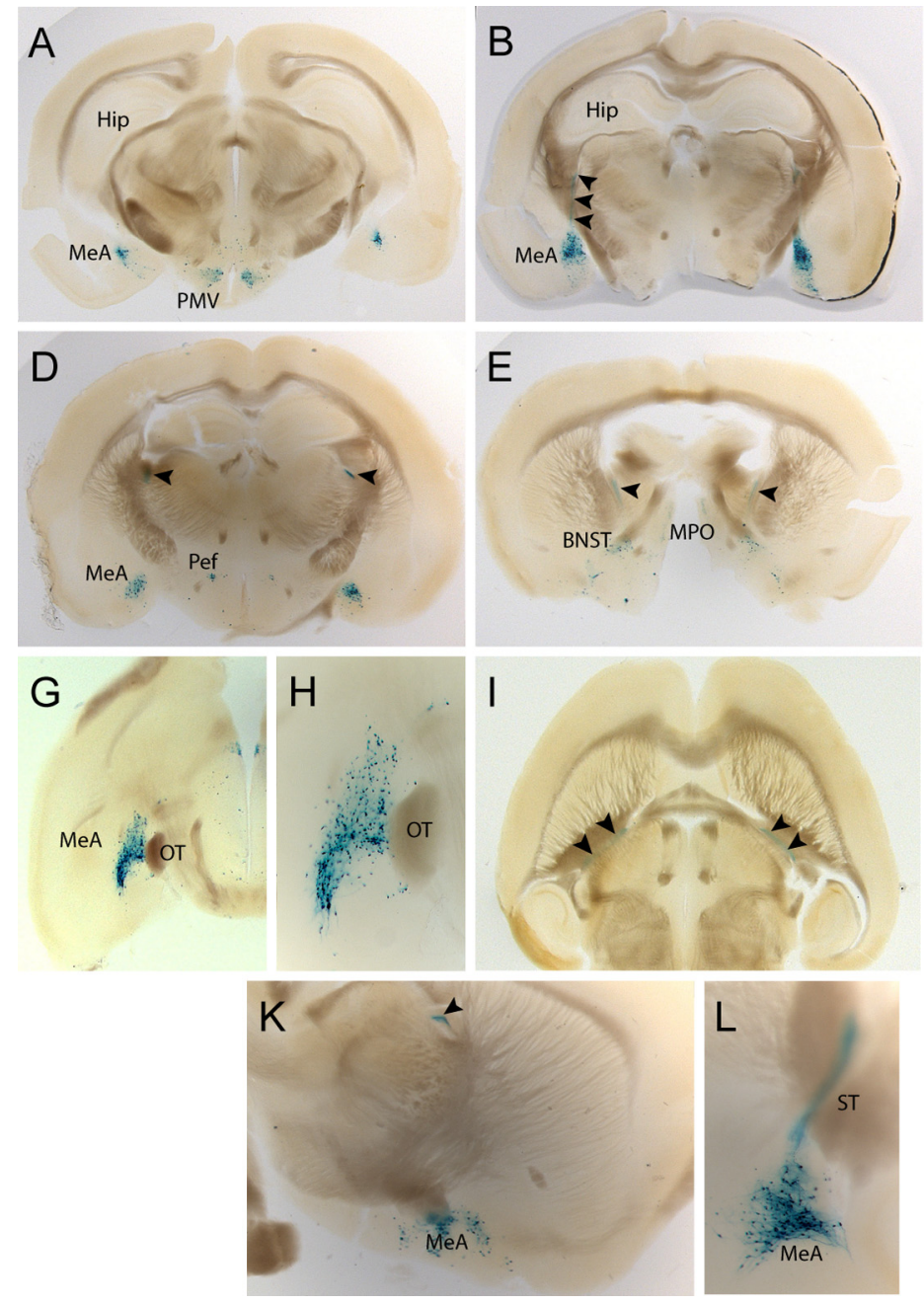

Figure 3. UCN3-expressing neurons of the medial amygdala project via the stria terminalis. $\boldsymbol{A}-\boldsymbol{F}$, Coronal sections from caudal to rostral illustrating the full extension of UCN3-expressing neurons within the MeA. B,C,X-Gal-positive neurons of the posterodorsal part of the MeA send their axonal projections (black arrowheads) dorsally. $\boldsymbol{D}-\boldsymbol{F}, \mathrm{X}$-Gal-stained axons continue horizontally at the level of the Pef $(\boldsymbol{D})$ before they descend toward the BNST $(\boldsymbol{E}, \boldsymbol{F}) . \boldsymbol{G}, \boldsymbol{H}$, Horizontal sections demonstrating the rostrocaudal distribution of UCN3-expressing neurons in the MeA. $I, J$, Horizontal view on axons originating in the MeA and projecting via the stria terminalis to the BNST. $\boldsymbol{K}, \boldsymbol{L}$, Sagittal view of the MeA at the level at which the axons turn rostrally $(\boldsymbol{K})$ and more lateral view depicting the posterodorsal part of the MeA with originating axons $(\boldsymbol{L})$.

\section{Anxiety- and depression-related behaviors are unchanged in $U c n 3^{t Z}$ mice}

For the comprehensive analysis of a wide range of behavioral parameters, we initially subjected $U c n 3^{t Z}$ mice to the modified hole board test (Ohl et al., 2001) within the behavioral phenotyping module of the German Mouse Clinic (Gailus-Durner et al., 2005). Behavioral analyses of two independent cohorts of wildtype and knock-out mice of both sexes did not reveal significant and reproducible genotype-dependent alterations in any of the parameters evaluated (supplemental Tables 1, 2, available at www.jneurosci.org as supplemental material). Nevertheless, UCN3 has been reported to produce anxiolytic-like effects after intracerebroventricular application (Valdez et al., 2003). Therefore, anxiety-like behavior of $U c n 3^{t Z}$ mice was assessed in an anxiety-specific behavioral test - the elevated plus maze (EPM). However, behavioral analysis of anxiety-related behavior in the EPM did not reveal any genotype effects. $U c n 3^{t Z / t Z}$ mice did not differ significantly from $U c n 3^{+/+}$littermates in the number of open arm entries (males: $\left.t_{(17)}=0.01, p=0.496\right)$ (Fig. $\left.6 A\right)(\mathrm{fe}-$ males: $t_{(22)}=0.72, p=0.240$ ) (Fig. $6 A$ ) and percentage time

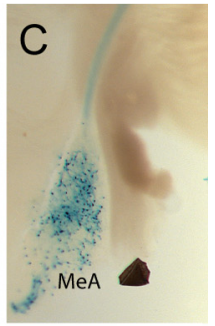

spent on open arms (males: $t_{(17)}=0.22$, $p=0.415)$ (Fig. $6 B$ ) (females: $t_{(22)}=1.55$, $p=0.068$ ) (Fig. $6 B$ ). There also were no significant differences in closed arm entries or any other EPM parameter (data not shown). Similarly, analysis of anxietyrelated behavior in the social interaction test did not reveal any significant genotype effect in active (males: MannWhitney $U=14, n=5-7, p=0.319$, one-tailed) (Fig. 6C) (females: MannWhitney $U=8, n=5-6, p=0.123$, one-tailed) (Fig. 6C) or passive (data not shown) social interaction.

Recently, it has been demonstrated that UCN2 and UCN3 produce antidepressant-like effects in the forced-swim test (FST). Testing $U c n 3^{t Z}$ mice in the FST procedure did not detect any difference between $U c n 3^{t Z / t Z}$ and $U c n 3^{+/+}$mice in floating (Fig. 6D), struggling, or swimming behavior (data not shown), neither in total nor in the time course of the $6 \mathrm{~min}$ test: interaction genotype by time floating: $F_{(5,54)}=1.05, p=0.397$; struggling: $F_{(5,54)}=$ $1.49, p=0.208$; swimming: $F_{(5,54)}=0.49$, $p=0.782$.

The acoustic startle reflex is considered to reflect aspects of anxiety (Holmes, 2001). A clear link between startle and anxiety states has been demonstrated for posttraumatic stress disorder and panic disorder (Grillon et al., 1994). ASV30 (antisauvagine-30), a specific CRH-R2 antagonist, has been demonstrated to reduce startle response and PPI, whereas UCN3 itself is able to increase startle as well as PPI in mice (Risbrough et al., 2004). Female $U c n 3^{t Z}$ mice of both genotypes presented with a lower startle amplitude than males, but there was no significant genotype effect on the startle response curves in either sex (for males: $F_{(8,20)}=2.25, p=0.068$ ) (Fig. $6 E$ ) (for females: $F_{(8,19)}=1.35, p=$ 0.280 ) (Fig. $6 E$ ). Males and females did not differ in their levels of PPI, and there was also no significant genotype effect in PPI at any prepulse intensity (for males: genotype by prepulse intensity interaction: $F_{(4,25)}=1.28, p=0.305$ ) (Fig. $6 F$ ) (for females: genotype by prepulse intensity interaction: $\left.F_{(4,24)}=1.01, p=0.424\right)$ (Fig. 6F).

\section{$\mathrm{Ucn} 3^{t Z}$ mice display altered social discrimination abilities}

$\mathrm{UCN} 3$ is predominantly expressed in nuclei such as the MeA, $\mathrm{BNST}$, and MPO, which are closely related to the main and accessory olfactory systems. These nuclei have been demonstrated to be critically relevant for expression of social behaviors. Therefore, we investigated the social discrimination abilities of male $U_{c n} 3^{+/+}$and $U c n 3^{t Z / t Z}$ mice. After an interexposure interval of $2 \mathrm{~h}$, wild-type and mutant male mice were clearly able to discriminate between subjects as indicated by the significantly reduced time they spent investigating a familiar compared with an unfamiliar subject (Fig. 7A). However, this memory extinguished in $U_{c n} 3^{+/+}$mice after an interexposure interval of $4 \mathrm{~h}$, whereas 

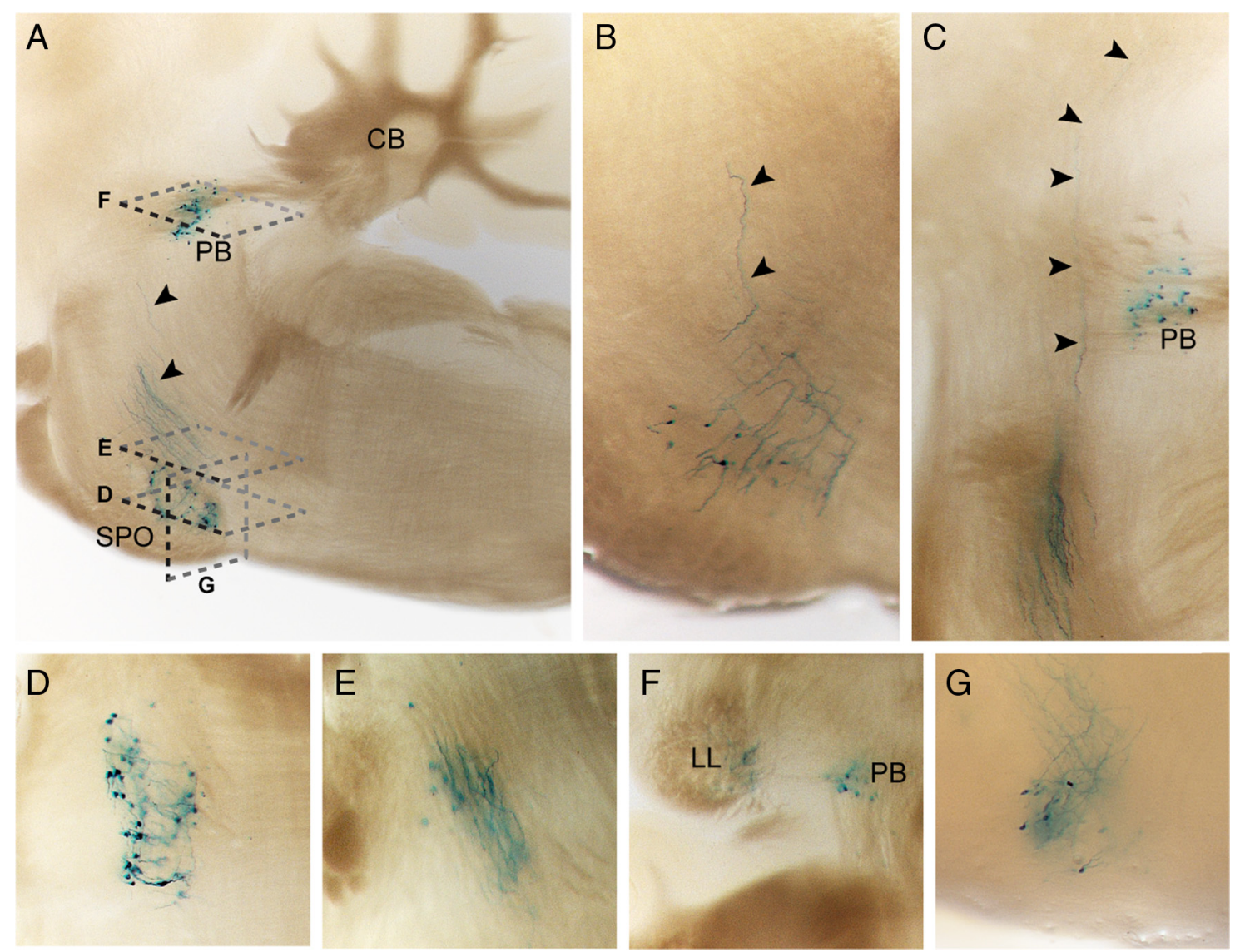

Figure 4. UCN3-expressing neurons of the superior paraolivary nucleus project via the lateral lemniscus to the inferior colliculus. $A-C$, Sagittal sections illustrating UCN3-expressing neurons residing in the SPO and their ascending axons, as indicated by black arrowheads. $\boldsymbol{D}-\boldsymbol{F}$, Horizontal sections from ventral to dorsal (compare $\boldsymbol{A}$ ) depicting UCN3-expressing neurons and their axons ascending via the LL. G, Coronal section demonstrating the origin and initial course of $X$-Gal-stained axons.

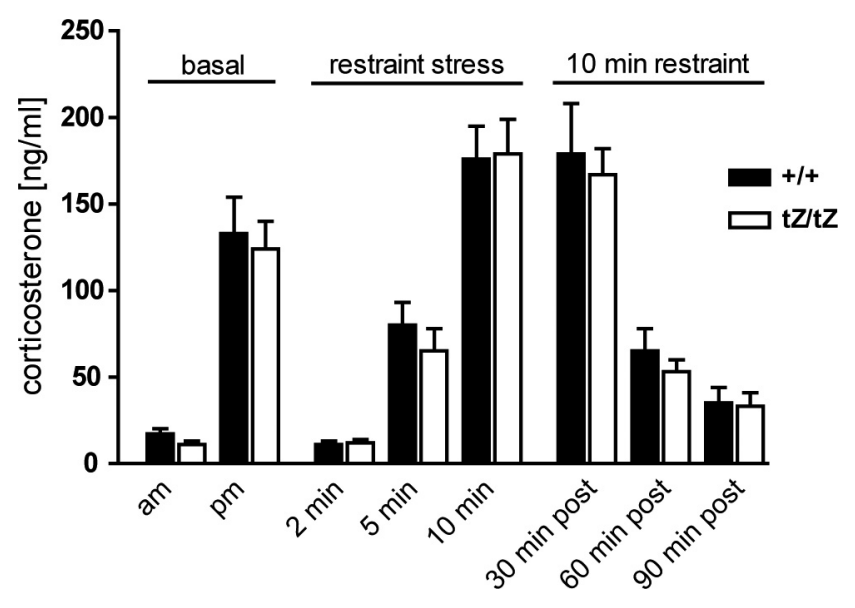

Figure 5. The HPA axis activity in male $U c n 3^{t z}$ mice is normal. Male $U c n 3^{t z / t z}$ mice showed no differences in basal plasma corticosterone levels in the morning $(\mathrm{am})$ or evening $(\mathrm{pm})$. Restraint stress resulted in significantly elevated corticosterone levels in male $U \mathrm{cn}^{3^{t Z} / \mathrm{tz}}$ mice and wildtype littermates. No difference was observed in negative-feedback regulation of HPA axis activity 30,60, and $90 \mathrm{~min}$ after $10 \mathrm{~min}$ restraint stress. Error bars indicate SEM.

male $U c n 3^{t Z / t Z}$ mice still spent more time investigating the unfamiliar subject (Fig. 7B). After an interexposure interval of $6 \mathrm{~h}$, $U c n 3^{t Z / t Z}$ mice were also unable to discriminate between a familiar and an unfamiliar subject (Fig. 7C). When calculating a preference index $=$ unfamiliar/(unfamiliar + familiar) for subject recognition, and analyzing social recognition indices of both ge- notypes for the $2 \mathrm{~h}$ interexposure interval and the $4 \mathrm{~h}$ interexposure interval by a two-way ANOVA for the factors genotype and time, we found a significant genotype by time interaction: $F_{(1,44)}=4.37, p<0.05$, indicating that social memory is the same in both genotypes after $2 \mathrm{~h}$, but extinguishes after $4 \mathrm{~h}$ in controls, but not in mutants. Thus, mutants demonstrated a slower extinction in this memory task.

This finding was confirmed in three independent cohorts of mice tested in the social discrimination task (data not shown). Additionally, we could demonstrate that also female $U c n 3^{t Z / t Z}$ mice presented with an improved social memory compared with wild-type littermates. After an interexposure interval of $1 \mathrm{~h}$, female $U c n 3^{+/+}$and $U c n 3^{t Z / t Z}$ mice were able to discriminate between subjects (data not shown), whereas after an interexposure interval of $2 \mathrm{~h}$ only $U c n 3^{t Z / t Z}$ mice spent significantly more time investigating the unfamiliar subject (Fig. 7D). Moreover, male CRH-R2 knock-out mice also showed an improved social memory compared with their wild-type littermates. After an interexposure interval of $1 \mathrm{~h}, \mathrm{CRH}-\mathrm{R} 2$ wild-type and knock-out mice were able to discriminate between subjects (data not shown), whereas after an interexposure interval of $2 \mathrm{~h}$, only CRH-R2 knock-out mice spent significantly more time investigating the unfamiliar subject (Fig. 7E).

$\mathrm{UCN} 2$ is the closest relative of UCN3 and also binds exclusively to the CRH-R2. In analogy to $U c n 3^{t Z}$ mice, we have generated UCN2 knock-out mice by substitution of the entire ORF by a $t Z$ reporter gene (supplemental Fig. $1 A-F$, available at www. jneurosci.org as supplemental material). In contrast to $U c n 3^{t Z}$ 
A Open arm entries

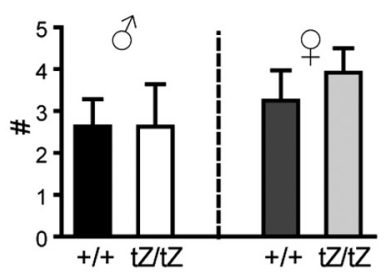

C

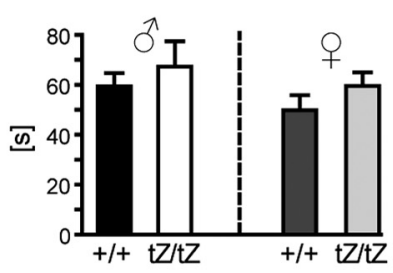

$\mathrm{E}$

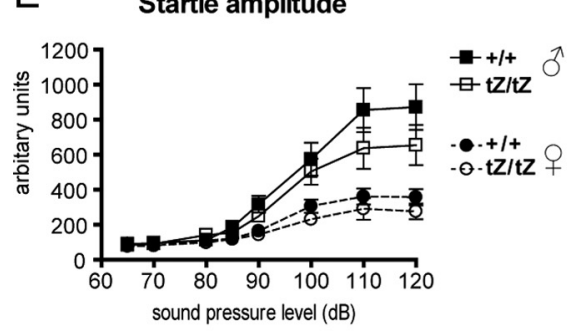

B \% Time on open arms

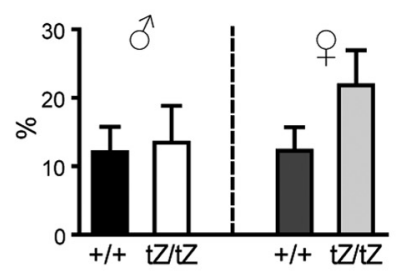

D

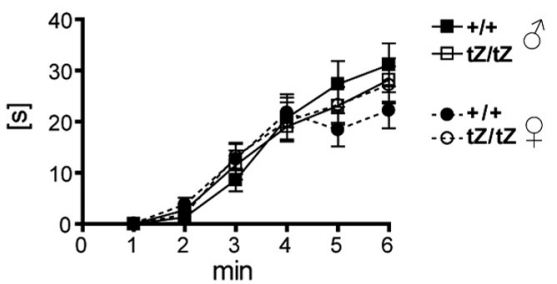

F

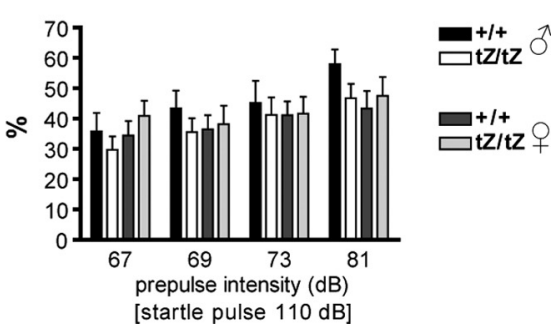

Figure 6. Anxiety- and depression-related behaviors are unchanged in male and female $U c n 3^{t z}$ mice. $A, B$, In the elevated plus maze test, male and female $U \mathrm{cn}^{\mathrm{tZ} / \mathrm{tz}}$ and $U \mathrm{cn} 3^{+/+}$mice did not show any differences when comparing open arm entries $(A)$ and total time on open arms $(\boldsymbol{B})$ (males, $n=8-11$ mice per genotype; females, $n=12$ mice per genotype). $\boldsymbol{C}$, The active social interaction time was identical for male and female $U \mathrm{cn}^{3 \mathrm{tZ} / \mathrm{tz}}$ and $U \mathrm{Cn} 3^{+/+}$mice as assessed in the social interaction test $(n=5-7$ mice per genotype). $\boldsymbol{D}$, No difference in floating behavior in a $6 \mathrm{~min}$ forced-swim test was observed ( $n=15$ mice per genotype). $\boldsymbol{E}, \boldsymbol{F}$, The acoustic sensorimotor behavior of male and female $U \mathrm{cn} 3^{t z / t z}$ and $U \mathrm{cn}^{+/+}$littermate control mice is not significantly different. $\boldsymbol{E}, \boldsymbol{F}$, Intensity-response curves of acoustic startle amplitudes $(\boldsymbol{E})$ and percentage of prepulse inhibition of the acoustic startle reflex at four prepulse intensities (startle pulse, $110 \mathrm{~dB} ; n=15$ mice per genotype) $(\boldsymbol{F})$ revealed no differences between male and female $U \mathrm{Cn} 3^{\text {tz } / t z}$ and $U \mathrm{cn} 3^{+/+}$littermates. Error bars indicate SEM.

mice, $U c n 2^{t Z / t Z}$ did not display any differences in the social discrimination test compared with $U c n 2^{+/+}$mice (Fig. $7 F$ ).

Finally, to exclude the possibility that the differences in social discrimination abilities are based on alterations in smelling ability, we performed a discriminatory odor perception task. Both $U_{c n} 3^{+/+}$and $U c n 3^{t Z / t Z}$ mice were able to discriminate between a neutral and an unfamiliar social odor (Fig. $7 G$ ). Both groups spent significantly more time exploring the social stimulus than the neutral one $\left(U c n 3^{t Z / t Z}, p<0.001 ; U c n 3^{+/+}, p<0.01\right.$; genotype by odor interaction: $\left.F_{(1,18)}=0.05 ; p=0.817\right)$. There was no significant difference between genotypes. Furthermore, the olfactory capabilities were further explored by subjecting the mice to an olfactory discrimination task and by assessing the animals' smell sensitivity. In both tasks, $U c n 3^{t Z / t Z}$ mice performed in the same range as $U_{c n} 3^{+/+}$control mice (Fig. $7 \mathrm{H}, I$ ). Together, these results suggest that $\mathrm{UCN} 3$, in addition to its specific receptor $\mathrm{CRH}-\mathrm{R} 2$, are involved in processes relevant to social behavior.

$\mathrm{Ucn} 3^{t Z}$ mice display normal nonsocial memory performance To assess whether the observed altered social discrimination abilities of $U c n 3^{t z / t z}$ mice are attributable to a generalized enhancement of memory performance or are specific to social memory, we tested $U c n 3^{+/+}$and $U c n 3^{t Z / t Z}$ mice in the object recognition and fear conditioning procedure.
In the object recognition procedure, male $U c n 3^{+/+}$and $U c n 3^{t Z / t Z}$ mice both explored the unfamiliar object more than the familiar one after $3 \mathrm{~h}$ (Fig. $8 \mathrm{~A}$ ) (genotype: $F_{(1,1)}=0.05, p=0.821$; object: $F_{(1,1)}=$ 9.85, $p<0.01$; interaction genotype by object: $\left.F_{(1,19)}=0.4, p=0.535\right)$, indicating intact object memory after $3 \mathrm{~h}$ in both genotypes. After $24 \mathrm{~h}$, both genotypes did not explore the unfamiliar object more than the familiar one (Fig. $8 \mathrm{~A}$ ) (genotype: $F_{(1,1)}=1.21, p=0.285$; object: $F_{(1,1)}=$ $0.9, p=0.356$; interaction genotype by object: $\left.F_{(1,20)}=0.01, p=0.909\right)$. When calculating a preference index $=$ unfamiliar/(unfamiliar + familiar) as it was done for subject recognition, analysis of the object recognition indices of both genotypes for the $3 \mathrm{~h}$ intertrial interval and the $24 \mathrm{~h}$ intertrial interval by two-way ANOVA did not yield any significant genotype by time interaction: $F_{(1,39)}=0.44, p=0.511$. There were also no differences between the genotypes in habituation to object exploration over the three sample phases: genotype: $F_{(1,2)}=0.52, p=0.478$; time: $F_{(2,2)}=9.63, p<0.001$; interaction genotype by time: $F_{(2,40)}=0.42, p=0.662$ (data not shown). Thus, male $U c n 3^{t Z}$ mice did not differ in rate of habituation or rate of extinction in the object memory task. Also, female $U c n 3^{+/+}$and $U c n 3^{t Z / t Z}$ were indistinguishable in their performance in the object recognition task (Fig. 8 B) (statistics not shown).

In the fear conditioning procedure, mice showed a stronger freezing response in the conditioning context than in the grid context and the neutral context (context: $\left.F_{(2,36)}=206.7, p<0.0001\right)$, independently of the genotype of the mice (genotype: $F_{(1,18)}=0.217, p=0.647$; genotype by context: $\left.F_{(2,36)}=0.774, p=0.468\right)$. This indicates that $U c n 3^{+/+}$ and $U c n 3^{t Z I t Z}$ formed a similarly strong and specific contextual fear memory. Mice showed a strong increase in freezing on tone presentation compared with the preceding $3 \mathrm{~min}$ baseline period $1 \mathrm{~d}$ after conditioning (Fig. 8C) (d1t vs Cy, $p<0.001$ ). However, both expression and extinction of auditory fear conditioning was similar for the two genotypes (genotype: $F_{(1,18)}=0.093, p=$ 0.764 ; day: $F_{(1,18)}=24.3, p<0.0001$; genotype by day: $F_{(1,18)}=$ $0.041, p=0.851)$.

Together, these results suggest that the observed memory phenotype of $U c n 3^{t Z / t Z}$ mice is mostly specific to social learning.

\section{Discussion}

Using previous findings from CRH-R2-deficient mice as a starting point, we initially focused our comprehensive analysis of UCN3-deficient mice on anxiety- and depression-like behavior, as well as on neuroendocrine stress adaptation.

The role of UCN3 in anxiety- and depression-related behavior The role of UCN3's cognate receptor CRH-R2 in anxiety-related behavior is currently somewhat unclear and controversial. Results based on selective CRH-R2 agonists including UCN3 
A IEI 2h

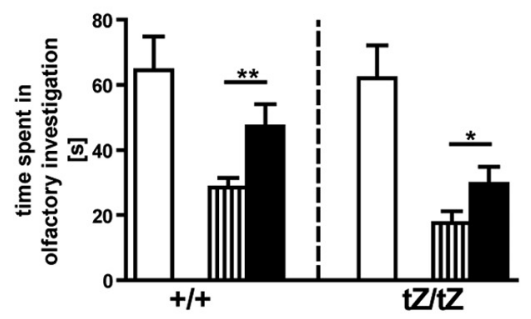

C

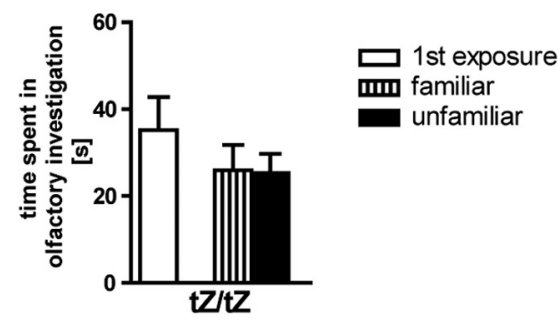

E

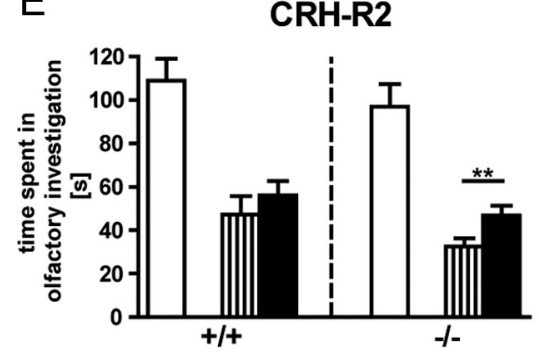

G

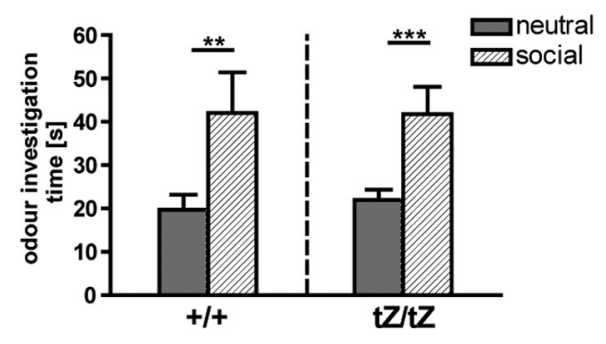

B

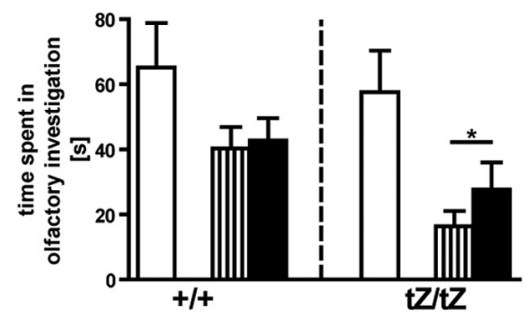

D

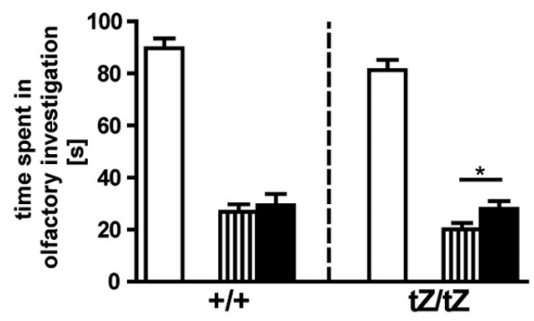

F

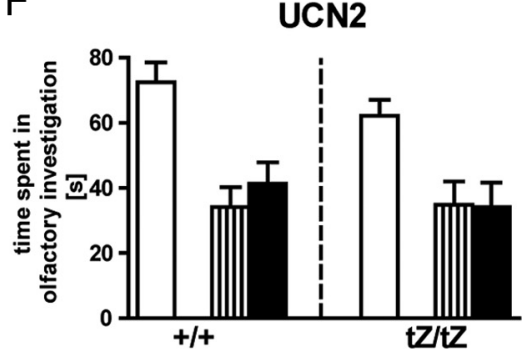

$\mathrm{H}$

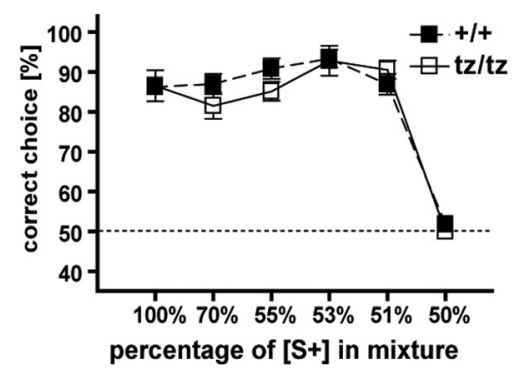

I

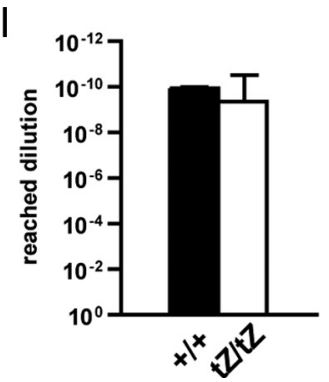

Figure 7. $U c n 3^{t Z}$ mice display altered social discrimination abilities. $\boldsymbol{A}-\boldsymbol{F}$, Investigation duration (in seconds) (mean + SEM) toward conspecific ovariectomized female. The white bars represent the duration during first exposure, and the hatched (same ovariectomized female) or black (novel ovariectomized female) bars, that of the second exposure $\left({ }^{*} p<0.05,{ }^{* *} p<0.01\right.$, familiar vs unfamiliar conspecific). $A-C$, Social discrimination abilities of male $U c n 3^{\text {tz } / t z}$ and $U c n 3^{+1+}$ mice after interexposure intervals of 2,4 , and $6 \mathrm{~h}$ ( $n=12$ mice per genotype). $\boldsymbol{D}$, Female $U c n 3^{t Z / t z}$ mice are able to discriminate between a familiar and an unfamiliar conspecific, whereas $U \mathrm{cn} 3^{+/+}$mice cannot $\left(n=12\right.$ animals per genotype; interexposure interval, $2 \mathrm{~h} ;{ }^{*} p<0.05$, familiar vs unfamiliar conspecific). $\boldsymbol{E}$, Male $\left(r h r 2^{-1-}\right.$ mice are able to discriminate between a familiar and an unfamiliar conspecific, whereas Crhr2 ${ }^{+/+}$mice cannot $\left(n=12\right.$ mice per genotype; interexposure interval, $2 \mathrm{~h}$ ). $\boldsymbol{F}$, Both $U \mathrm{cn} 2^{t z / t z}$ and $U c n 2^{+/+}$mice are unable to discriminate between a familiar and an unfamiliar conspecific ( $n=12$ mice per genotype; interexposure interval, $2 \mathrm{~h}$ ). IEl, Interexposure interval. G, Investigation time of male $U \mathrm{cn} 3^{t Z / t Z}$ and $U \mathrm{cn} 3^{+/+}$littermate control mice at a neutral and a social odor

(Pelleymounter et al., 2002, 2004; Valdez et al., 2002, 2003; Risbrough et al., 2003, 2004; Venihaki et al., 2004) or antagonists (Radulovic et al., 1999; Bakshi et al., 2002) as well as CRH-R2-deficient mice (Bale et al., 2000; Coste et al., 2000; Kishimoto et al., 2000) suggest both anxiogenic and anxiolytic effects caused by CRH-R2 receptor activation, which highly depends on drug dose, brain location, or test conditions. The function of CHR-R2 in depression-related behavior as assessed by antidepressant screening procedures, such as the FST and tail suspension test, is more consistent. Stimulation of CRH-R2 by UCN2 or UCN3 has been demonstrated to reduce immobility (Tanaka and Telegdy, 2008a,b), a finding in line with the genetic ablation of CRH-R2, which leads to increased immobility (Bale and Vale, 2003; Todorovic et al., 2009). However, the comprehensive behavioral phenotyping of UCN3-deficient mice in this study did not show any alterations in measures of anxiety- or of depression-related behaviors. Nevertheless, we cannot fully exclude that other procedures assessing anxiety- and depression-related behavior, different from those used here, could reveal genotype-dependent differences. Along those lines, conditions of acute or chronic stress could also have an impact on the expression of potential genotype dependent differences in emotional behavior. Finally, it has to be remarked that discrepancies between acute pharmacological treatment and respective knockout mice are often observed likely because of well known mechanisms related to incomplete specificity or penetrance of administered compounds on the one hand as well as to compensatory mechanisms activated by constitutive loss of gene function on the other hand (Holmes, 2008).

stimulus in a discriminatory task $(n=19-21$ mice per genotype). Both groups significantly discriminated between the neutral and the social stimulus $\left({ }^{* *} p<0.01,{ }^{* * *} p<0.001\right.$, neutral vs social odor). $\boldsymbol{H}$, Fine olfactory discrimination with male $U \mathrm{cn}^{+/+}$and $U \mathrm{cn} 3^{\text {tz } / \mathrm{tz}}$ mice. Ratios along the $x$-axis represent the concentration of $[S+]$ in the binary mixture of $[S+]$ and $[S-]$. The number of successful discriminations per session is expressed as mean percentage of first correct responses to the rewarded odorant $[S+]$ of total trials per session [Mann-Whitney tests: 100\% $p=0.6467$, MannWhitney U (MWU) 48.00; 70\% $p=0.2099$, MWU 40.50; $55 \%$ $p=0.1579, \operatorname{MWU} 34.50 ; 53 \% p=0.5746, \operatorname{MWU} 56.50 ; p=$ $0.2592,38.50 ; 50 \% p=0.3241$, MWU 49.50]. I, Smell sensitivity test with male $U \mathrm{cn} 3^{+/+}$and $U \mathrm{cn} 3^{\text {tz } / t z}$ mice. Discrimination between a dish scented with $[S+]$ in different steps of dilution and another dish with solvent (Mann-Whitney test: $p=0.0992$, MWU 39.00). 


\section{A

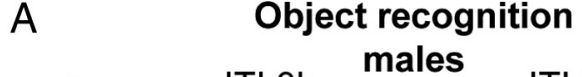

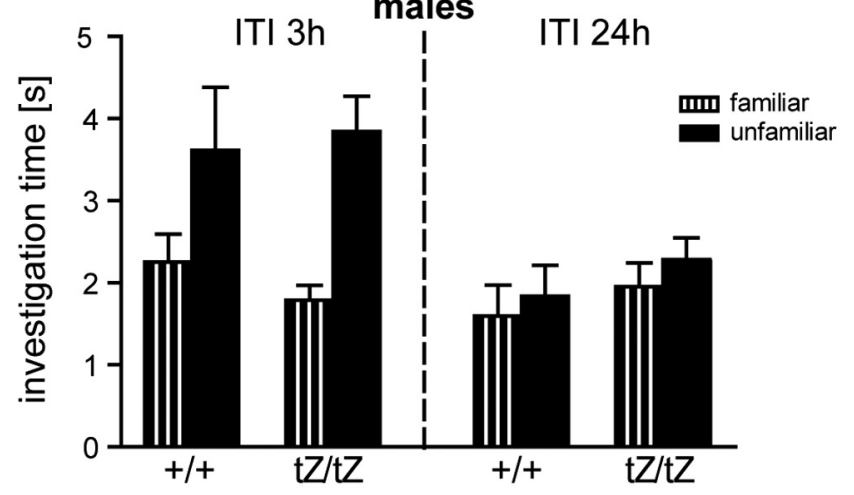

B

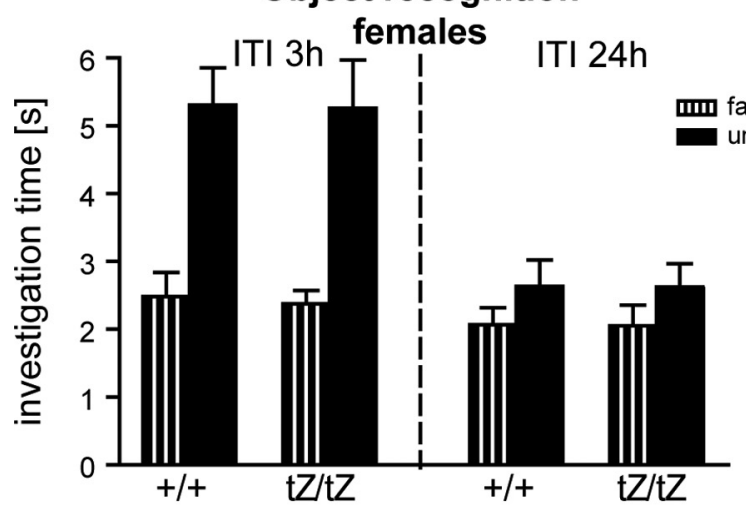

C

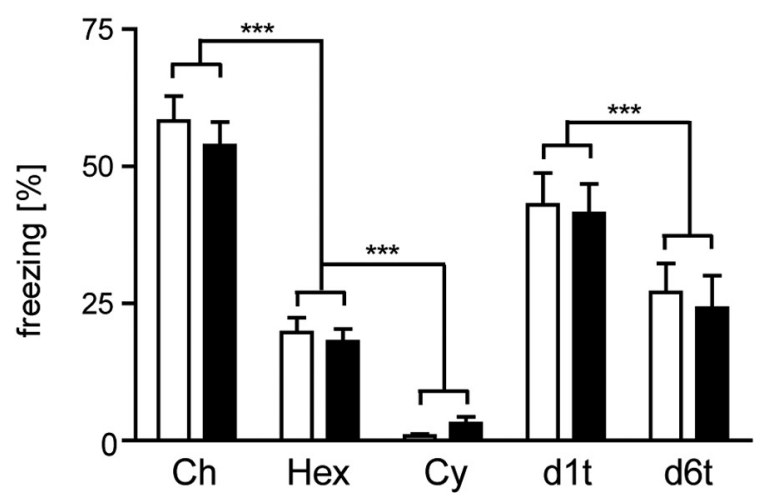

Figure 8. $U c n 3^{t Z}$ mice display normal memory performance. $A, B, 0$ bject recognition memory of male $(n=10-12)(\boldsymbol{A})$ and female $(n=12-13)(\boldsymbol{B}) U \mathrm{c} n 3^{t z}$ mice. Investigation time at a familiar and an unfamiliar object $3 \mathrm{~h}$ (left panel) and $24 \mathrm{~h}$ (right panel) after the last sample phase; shown are mean + SEM. ITI, Intertrial interval. C, Contextual and auditory-cued fear. Left panel, Freezing responses of $U c n 3^{+/+}$(open bars; $n=9$ ) and $U c n 3^{t Z / t z}$ mice (filled bars; $n=11$ ) on (re-)exposure to the conditioning chamber $(\mathrm{Ch})$, a hexagonal prism containing a grid floor (Hex), and a neutral cylindrical context (Cy) for 3 min each $1 \mathrm{~d}$ after conditioning. Right panel, Freezing responses of the same mice on exposure to 3 min tones in the neutral cylindrical context $1 \mathrm{~d}(\mathrm{~d} 1 \mathrm{t})$ and $6 \mathrm{~d}(\mathrm{~d} 6 \mathrm{t})$ after conditioning. Shown are mean + SEM. ${ }^{* * *} p<0.001$.

\section{The role of UCN3 in HPA axis function}

CRH-R2 has been postulated to modulate the neuroendocrine stress response, in particular after the initial activation of the HPA axis as well as the later recovery phase (Coste et al., 2001). However, male UCN3-deficient mice exhibited normal basal plasma corticosterone levels compared with wild-type littermates and did not show any alterations in the stress-induced activation or in the negative-feedback regulation of the HPA axis. Similarly, no sex-specific differences in regulation of the HPA axis were observed, as recently demonstrated for CRH-R2 and UCN2 knock-out mice (Chen et al., 2006).

\section{The central and peripheral expression of UCN3}

UCN3 is highly expressed in discrete nuclei of the murine CNS in a spatial pattern, which is clearly distinguishable from that of the other CRH-R2 ligands. Using the $t Z$ reporter gene, we confirmed the expression in all previously described brain nuclei and we additionally identified previously unrecognized expression domains (i.e., in the PMV and in the PB). The expression in the PB was independently confirmed by using in situ hybridization directly detecting $U_{c n} 3$ mRNA. In contrast, the expression in the PMV could not be confirmed on mRNA level. This discrepancy in the expression of $t Z$ and endogenous $U c n 3$ may be attributable to differences in the sensitivities of the used detection assays or attributable to cell type-specific differences in the stability of $t Z$ and $U c n 3$ mRNA. The expression of UCN3 in the PMV is also supported by the immunohistochemical detection of UCN3positive fibers ( $\mathrm{Li}$ et al., 2002), which Cavalcante et al. (2006) assigned to UCN3-expressing neurons in the MeA and Pef, but which could also be of local origin. In peripheral organs, strong $\beta$-galactosidase staining was observed in pancreatic islets as previously described ( $\mathrm{Li}$ et al., 2003). Moreover, we could identify UCN3-specific cells within the duodenum (i.e., a subset of mucosa producing goblet cells as well as cells within the intestinal crypts). Notably, the $U c n 3^{t Z}$ reporter mouse line clearly demonstrated the absence of UCN3 expression in all other organs of the adult mouse, including the pituitary and adrenal gland, in accordance with previous reports (Lewis et al., 2001).

Li et al. (2002) have demonstrated a significant overlap of UCN3-positive fibers with sites of CRH-R2 expression. However, their immunohistochemical approach did not allow the tracking of the origin of these fibers to deduce ligand-receptor connectivities. Therefore, we used $t Z$, a well established genetically encoded anterograde tracer (Mombaerts et al., 1996), to visualize the axonal projections of UCN3-expressing neurons. Although the majority of UCN3-positive neurons in the brain displayed only locally restricted X-Gal-stained neurites, all neurons of the SPO and neurons located within the MeApd showed long-distance connections. The relatively small population of SPO neurons ( $\sim 30$ neurons) projected via the lateral lemniscus to the inferior colliculus, which is a major site of CRH-R2 expression (Van Pett et al., 2000). In contrast to the SPO, where individual axons can be tracked to their final targeting area, the axons of UCN3expressing neurons within the posterodorsal part of the MeA fasciculate and project as a compact bundle rostrally via the stria terminalis. Presynaptic terminals are not labeled by $t Z$ because microtubules are excluded from nerve terminals; however, we can clearly hypothesize that this axon bundle terminates in the posterior BNST. This division of the BNST has been described as a major target of MeApd projections (Dong et al., 2001; Usunoff et al., 2009) and is one of the sites of highest CRH-R2 expression in the brain (Van Pett et al., 2000). Surprisingly, no projections to the lateral septum were detected, although it strongly expresses CRH-R2 and it is penetrated by a dense network of UCN3immunoreactive fibers (Li et al., 2002). Tau and consequently the tau- $\beta$-galactosidase fusion protein are predominantly present in axons (Dehmelt and Halpain, 2005) and fully excluded from distal portions of dendrites. This suggests that not axon terminals, but rather dendrites of currently unknown origin, account for the dense network of UCN3-immunoreactive fibers in the LS. 


\section{UCN3 in the accessory olfactory system}

The visualization of UCN3-expressing neurons using the $t Z$ reporter gene substantiates the observation that UCN3 is predominantly expressed in nuclei connected to the accessory olfactory system (AOS) (i.e., the MeA, the BNST, and the MPO) (Cooke et al., 1998). Moreover, the lateral septum is interspersed with UCN3-immunoreactive fibers (Li et al., 2002) and strongly expresses CRH-R2, which is additionally present in the MeA and the BNST (Van Pett et al., 2000). The AOS consists of a multisynaptic circuit that originates in a sense organ, the vomeronasal organ, and ends in endocrine, motivational, and motor centers such as the hypothalamus, basal ganglia, and brainstem, respectively (Cooke et al., 1998).

Social behaviors are regulated by hormonal and chemosensory signals such as conspecific odors that activate the vomeronasal organ and are integrated in nuclei of the extended amygdala (Newman, 1999). The MeA is primarily involved in social recognition and learning (Vochteloo and Koolhaas, 1987; Ferguson et al., 2001) as well as the initiation of social behaviors such as sexual behavior (Harris and Sachs, 1975) and aggression (Kemble et al., 1984). In particular, the posterodorsal part of the medial nucleus of the amygdala receives its major sensory input from the accessory olfactory bulb and is characterized by projections to the principal nucleus of the BNST (Canteras et al., 1995) and to the MPO as well as to other often sexually dimorphic hypothalamic nuclei (Simerly, 2002; Usunoff et al., 2009). Using the $t Z$ reporter gene, we could confirm the strong expression of UCN3 in the $\mathrm{MeA}$ and were able to demonstrate that the UCN3-expressing neurons in the MeApd neurons project to the principal nucleus of the BNST.

\section{The role of UCN3 in social behavior}

Considering the expression patterns of CRH-R2 and UCN3, it is surprising that their impact on other aspects of behavior in addition to anxiety- and depression-related behavior, and in particular social behavior, has only scarcely been studied until today. It is mostly accepted that the key systems involved in the modulation of complex social behaviors, including social recognition and social memory formation, are the related nonapeptides oxytocin (OT) and arginine vasopressin (AVP) (for review, see Landgraf and Neumann, 2004; Winslow and Insel, 2004; Donaldson and Young, 2008). Knock-out mice of the AVP receptor V1a or of OT manifest a deficit in social memory (Ferguson et al., 2000; Bielsky et al., 2004). In contrast, intracerebroventricular application of AVP increases social recognition in male rats (Engelmann et al., 1996). The site-specific injection of OT receptor agonists or antagonists has demonstrated a key role of the OT receptor in the MeA for social recognition (Ferguson et al., 2001). Nevertheless, it has been demonstrated that UCN1 and UCN3 modulate maternal behavior via CRH-R2 in the lateral septum (D'Anna et al., 2005; D'Anna and Gammie, 2009), and accordingly, CRH-R2 knock-out mice exhibit impaired maternal defense of their offspring (Gammie et al., 2005). Along these lines, UCN2 increases spontaneous parental behavior in prairie voles (Samuel et al., 2008). Evidence for an involvement of the CRH system in the modulation of social memory has been demonstrated by Heinrichs (2003) using CRH-R agonists and antagonists. To further elucidate the role of the CRH system in social behavior, we studied the social discrimination performance of UCN3, CRH-R2, and UCN2 knock-out mice. Social discrimination abilities were clearly altered in $U c n 3^{t Z / t Z}$ mice compared with wild-type littermates. In the social discrimination procedure, UCN3-deficient mice were able to memorize previously encountered conspecifics for a longer time than wild-type littermates. In contrast, UCN2deficient mice were indistinguishable from their wild-type littermates in the social discrimination task, suggesting a unique role of UCN3, which cannot be compensated by UCN2 or UCN1, the other ligands of CRH-R2. Moreover, this observation was confirmed in CRH-R2 knock-out mice, underscoring the specific importance of UCN3. Performance in the social recognition/discrimination task requires olfactory information retrieval, which was clearly not altered in UCN3-deficient mice. Finally, UCN3deficient mice showed a performance in nonsocial memory tasks that was indistinguishable from that of their wild-type littermates. In conclusion, these findings suggest a specific role of $\mathrm{UCN} 3$ and its receptor CRH-R2 in the processing of social cues as well as the formation and extinction of social memories.

\section{References}

Bakshi VP, Smith-Roe S, Newman SM, Grigoriadis DE, Kalin NH (2002) Reduction of stress-induced behavior by antagonism of corticotropinreleasing hormone 2 (CRH2) receptors in lateral septum or CRH1 receptors in amygdala. J Neurosci 22:2926-2935.

Bale TL, Vale WW (2003) Increased depression-like behaviors in corticotropin-releasing factor receptor-2-deficient mice: sexually dichotomous responses. J Neurosci 23:5295-5301.

Bale TL, Contarino A, Smith GW, Chan R, Gold LH, Sawchenko PE, Koob GF, Vale WW, Lee KF (2000) Mice deficient for corticotropin-releasing hormone receptor-2 display anxiety-like behaviour and are hypersensitive to stress. Nat Genet 24:410-414.

Bielsky IF, Hu SB, Szegda KL, Westphal H, Young LJ (2004) Profound impairment in social recognition and reduction in anxiety-like behavior in vasopressin V1a receptor knockout mice. Neuropsychopharmacology 29:483-493.

Bunting M, Bernstein KE, Greer JM, Capecchi MR, Thomas KR (1999) Targeting genes for self-excision in the germ line. Genes Dev 13:1524-1528.

Callahan CA, Thomas JB (1994) Tau-beta-galactosidase, an axon-targeted fusion protein. Proc Natl Acad Sci U S A 91:5972-5976.

Canteras NS, Simerly RB, Swanson LW (1995) Organization of projections from the medial nucleus of the amygdala: a PHAL study in the rat. J Comp Neurol 360:213-245.

Cavalcante JC, Sita LV, Mascaro MB, Bittencourt JC, Elias CF (2006) Distribution of urocortin 3 neurons innervating the ventral premammillary nucleus in the rat brain. Brain Res 1089:116-125.

Chen A, Zorrilla E, Smith S, Rousso D, Levy C, Vaughan J, Donaldson C, Roberts A, Lee KF, Vale W (2006) Urocortin 2-deficient mice exhibit gender-specific alterations in circadian hypothalamus-pituitary-adrenal axis and depressive-like behavior. J Neurosci 26:5500-5510.

Cooke B, Hegstrom CD, Villeneuve LS, Breedlove SM (1998) Sexual differentiation of the vertebrate brain: principles and mechanisms. Front Neuroendocrinol 19:323-362.

Coste SC, Kesterson RA, Heldwein KA, Stevens SL, Heard AD, Hollis JH, Murray SE, Hill JK, Pantely GA, Hohimer AR, Hatton DC, Phillips TJ, Finn DA, Low MJ, Rittenberg MB, Stenzel P, Stenzel-Poore MP (2000) Abnormal adaptations to stress and impaired cardiovascular function in mice lacking corticotropin-releasing hormone receptor-2. Nat Genet 24:403-409.

Coste SC, Murray SE, Stenzel-Poore MP (2001) Animal models of CRH excess and $\mathrm{CRH}$ receptor deficiency display altered adaptations to stress. Peptides 22:733-741.

D’Anna KL, Gammie SC (2009) Activation of corticotropin-releasing factor receptor 2 in lateral septum negatively regulates maternal defense. Behav Neurosci 123:356-368.

D'Anna KL, Stevenson SA, Gammie SC (2005) Urocortin 1 and 3 impair maternal defense behavior in mice. Behav Neurosci 119:1061-1071.

Dehmelt L, Halpain S (2005) The MAP2/Tau family of microtubuleassociated proteins. Genome Biol 6:204.

Deussing JM, Kühne C, Pütz B, Panhuysen M, Breu J, Stenzel-Poore MP, Holsboer F, Wurst W (2007) Expression profiling identifies the CRH/ CRH-R1 system as a modulator of neurovascular gene activity. J Cereb Blood Flow Metab 27:1476-1495.

Donaldson ZR, Young LJ (2008) Oxytocin, vasopressin, and the neurogenetics of sociality. Science 322:900-904. 
Dong HW, Petrovich GD, Swanson LW (2001) Topography of projections from amygdala to bed nuclei of the stria terminalis. Brain Res Brain Res Rev 38:192-246.

Ebner K, Wotjak CT, Landgraf R, Engelmann M (2002) Forced swimming triggers vasopressin release within the amygdala to modulate stresscoping strategies in rats. Eur J Neurosci 15:384-388.

Engelmann M, Wotjak CT, Landgraf R (1995) Social discrimination procedure: an alternative method to investigate juvenile recognition abilities in rats. Physiol Behav 58:315-321.

Engelmann M, Wotjak CT, Neumann I, Ludwig M, Landgraf R (1996) Behavioral consequences of intracerebral vasopressin and oxytocin: focus on learning and memory. Neurosci Biobehav Rev 20:341-358.

Feil R, Hölter SM, Weindl K, Wurst W, Langmesser S, Gerling A, Feil S, Albrecht U (2009) cGMP-dependent protein kinase I, the circadian clock, sleep and learning. Commun Integr Biol 2:298-301.

Fekete EM, Inoue K, Zhao Y, Rivier JE, Vale WW, Szücs A, Koob GF, Zorrilla EP (2007) Delayed satiety-like actions and altered feeding microstructure by a selective type 2 corticotropin-releasing factor agonist in rats: intra-hypothalamic urocortin 3 administration reduces food intake by prolonging the post-meal interval. Neuropsychopharmacology 32:10521068.

Ferguson JN, Young LJ, Hearn EF, Matzuk MM, Insel TR, Winslow JT (2000) Social amnesia in mice lacking the oxytocin gene. Nat Genet 25:284-288.

Ferguson JN, Aldag JM, Insel TR, Young LJ (2001) Oxytocin in the medial amygdala is essential for social recognition in the mouse. J Neurosci $21: 8278-8285$

File SE, Hyde JR (1978) Can social interaction be used to measure anxiety? Br J Pharmacol 62:19-24.

Friedrich G, Soriano P (1991) Promoter traps in embryonic stem cells: a genetic screen to identify and mutate developmental genes in mice. Genes Dev 5:1513-1523.

Gailus-Durner V, Fuchs H, Becker L, Bolle I, Brielmeier M, Calzada-Wack J, Elvert R, Ehrhardt N, Dalke C, Franz TJ, Grundner-Culemann E, Hammelbacher S, Hölter SM, Hölzlwimmer G, Horsch M, Javaheri A, Kalaydjiev SV, Klempt M, Kling E, Kunder S, et al. (2005) Introducing the German Mouse Clinic: open access platform for standardized phenotyping. Nat Methods 2:403-404.

Gailus-Durner V, Fuchs H, Adler T, Aguilar Pimentel A, Becker L, Bolle I, Calzada-Wack J, Dalke C, Ehrhardt N, Ferwagner B, Hans W, Hölter SM, Hölzlwimmer G, Horsch M, Javaheri A, Kallnik M, Kling E, Lengger C, Mörth C, Mossbrugger I, et al. (2009) Systemic first-line phenotyping. Methods Mol Biol 530:463-509.

Gammie SC, Hasen NS, Stevenson SA, Bale TL, D’Anna KL (2005) Elevated stress sensitivity in corticotropin-releasing factor receptor 2 deficient mice decreases maternal, but not intermale aggression. Behav Brain Res 160:169-177.

Golub Y, Mauch CP, Dahlhoff M, Wotjak CT (2009) Consequences of extinction training on associative and non-associative fear in a mouse model of posttraumatic stress disorder (PTSD). Behav Brain Res 205:544-549.

Grillon C, Ameli R, Goddard A, Woods SW, Davis M (1994) Baseline and fear-potentiated startle in panic disorder patients. Biol Psychiatry 35:431-439.

Harris VS, Sachs BD (1975) Copulatory behavior in male rats following amygdaloid lesions. Brain Res 86:514-518.

Heinrichs SC (2003) Modulation of social learning in rats by brain corticotropin-releasing factor. Brain Res 994:107-114.

Holmes A (2001) Targeted gene mutation approaches to the study of anxiety-like behavior in mice. Neurosci Biobehav Rev 25:261-273.

Holmes A (2008) Genetic variation in cortico-amygdala serotonin function and risk for stress-related disease. Neurosci Biobehav Rev 32:1293-1314.

Hsu SY, Hsueh AJ (2001) Human stresscopin and stresscopin-related peptide are selective ligands for the type 2 corticotropin-releasing hormone receptor. Nat Med 7:605-611.

Jamieson PM, Li C, Kukura C, Vaughan J, Vale W (2006) Urocortin 3 modulates the neuroendocrine stress response and is regulated in rat amygdala and hypothalamus by stress and glucocorticoids. Endocrinology 147:4578-4588.

Kamprath K, Wotjak CT (2004) Nonassociative learning processes determine expression and extinction of conditioned fear in mice. Learn Mem 11:770-786.
Kemble ED, Blanchard DC, Blanchard RJ, Takushi R (1984) Taming in wild rats following medial amygdaloid lesions. Physiol Behav 32:131-134.

Kishimoto T, Radulovic J, Radulovic M, Lin CR, Schrick C, Hooshmand F, Hermanson O, Rosenfeld MG, Spiess J (2000) Deletion of crhr2 reveals an anxiolytic role for corticotropin-releasing hormone receptor-2. Nat Genet 24:415-419.

Landgraf R, Neumann ID (2004) Vasopressin and oxytocin release within the brain: a dynamic concept of multiple and variable modes of neuropeptide communication. Front Neuroendocrinol 25:150-176.

Lewis K, Li C, Perrin MH, Blount A, Kunitake K, Donaldson C, Vaughan J, Reyes TM, Gulyas J, Fischer W, Bilezikjian L, Rivier J, Sawchenko PE, Vale WW (2001) Identification of urocortin III, an additional member of the corticotropin-releasing factor (CRF) family with high affinity for the CRF2 receptor. Proc Natl Acad Sci U S A 98:7570-7575.

Li C, Vaughan J, Sawchenko PE, Vale WW (2002) Urocortin IIIimmunoreactive projections in rat brain: partial overlap with sites of type 2 corticotrophin-releasing factor receptor expression. J Neurosci 22:991-1001.

Li C, Chen P, Vaughan J, Blount A, Chen A, Jamieson PM, Rivier J, Smith MS, Vale W (2003) Urocortin III is expressed in pancreatic beta-cells and stimulates insulin and glucagon secretion. Endocrinology 144:32163224.

Li C, Chen P, Vaughan J, Lee KF, Vale W (2007) Urocortin 3 regulates glucose-stimulated insulin secretion and energy homeostasis. Proc Natl Acad Sci U S A 104:4206-4211.

Mihalick SM, Langlois JC, Krienke JD, Dube WV (2000) An olfactory discrimination procedure for mice. J Exp Anal Behav 73:305-318.

Mombaerts P, Wang F, Dulac C, Chao SK, Nemes A, Mendelsohn M, Edmondson J, Axel R (1996) Visualizing an olfactory sensory map. Cell 87:675-686.

Newman SW (1999) The medial extended amygdala in male reproductive behavior. A node in the mammalian social behavior network. Ann N Y Acad Sci 877:242-257.

Ohata H, Shibasaki T (2004) Effects of urocortin 2 and 3 on motor activity and food intake in rats. Peptides 25:1703-1709.

Ohl F, Holsboer F, Landgraf R (2001) The modified hole board as a differential screen for behavior in rodents. Behav Res Methods Instrum Comput 33:392-397.

Pelleymounter MA, Joppa M, Ling N, Foster AC (2002) Pharmacological evidence supporting a role for central corticotropin-releasing factor(2) receptors in behavioral, but not endocrine, response to environmental stress. J Pharmacol Exp Ther 302:145-152.

Pelleymounter MA, Joppa M, Ling N, Foster AC (2004) Behavioral and neuroendocrine effects of the selective CRF2 receptor agonists urocortin II and urocortin III. Peptides 25:659-666.

Pham TT, Giesert F, Röthig A, Floss T, Kallnik M, Weindl K, Hölter SM, Ahting U, Prokisch H, Becker L, Klopstock T, Hrabé de Angelis M, Beyer K, Görner K, Kahle PJ, Vogt Weisenhorn DM, Wurst W (2010) DJ-1deficient mice show less TH-positive neurons in the ventral tegmental area and exhibit non-motoric behavioural impairments. Genes Brain Behav 9:305-317.

Radulovic J, Rühmann A, Liepold T, Spiess J (1999) Modulation of learning and anxiety by corticotropin-releasing factor (CRF) and stress: differential roles of CRF receptors 1 and 2. J Neurosci 19:5016-5025.

Reyes TM, Lewis K, Perrin MH, Kunitake KS, Vaughan J, Arias CA, Hogenesch JB, Gulyas J, Rivier J, Vale WW, Sawchenko PE (2001) Urocortin II: a member of the corticotropin-releasing factor (CRF) neuropeptide family that is selectively bound by type 2 CRF receptors. Proc Natl Acad Sci U S A 98:2843-2848.

Risbrough VB, Hauger RL, Pelleymounter MA, Geyer MA (2003) Role of corticotropin releasing factor (CRF) receptors 1 and 2 in CRF-potentiated acoustic startle in mice. Psychopharmacology (Berl) 170:178-187.

Risbrough VB, Hauger RL, Roberts AL, Vale WW, Geyer MA (2004) Corticotropin-releasing factor receptors CRF1 and CRF2 exert both additive and opposing influences on defensive startle behavior. J Neurosci 24:6545-6552.

Samuel PA, Hostetler CM, Bales KL (2008) Urocortin II increases spontaneous parental behavior in prairie voles (Microtus ochrogaster). Behav Brain Res 186:284-288.

Saruta M, Takahashi K, Suzuki T, Fukuda T, Torii A, Sasano H (2005) Urocortin 3/stresscopin in human colon: possible modulators of gastrointestinal function during stressful conditions. Peptides 26:1196-1206. 
Simerly RB (2002) Wired for reproduction: organization and development of sexually dimorphic circuits in the mammalian forebrain. Annu Rev Neurosci 25:507-536.

Soriano P (1999) Generalized lacZ expression with the ROSA26 Cre reporter strain. Nat Genet 21:70-71.

Tanaka M, Telegdy G (2008a) Antidepressant-like effects of the CRF family peptides, urocortin 1, urocortin 2 and urocortin 3 in a modified forced swimming test in mice. Brain Res Bull 75:509-512.

Tanaka M, Telegdy G (2008b) Involvement of adrenergic and serotonergic receptors in antidepressant-like effect of urocortin 3 in a modified forced swimming test in mice. Brain Res Bull 77:301-305.

Todorovic C, Sherrin T, Pitts M, Hippel C, Rayner M, Spiess J (2009) Suppression of the MEK/ERK signaling pathway reverses depressionlike behaviors of CRF2-deficient mice. Neuropsychopharmacology 34:1416-1426.

Tõnissaar M, Philips MA, Eller M, Harro J (2004) Sociability trait and serotonin metabolism in the rat social interaction test. Neurosci Lett 367:309-312.

Usunoff KG, Schmitt O, Itzev DE, Haas SJ, Lazarov NE, Rolfs A, Wree A (2009) Efferent projections of the anterior and posterodorsal regions of the medial nucleus of the amygdala in the mouse. Cells Tissues Organs 190:256-285.
Valdez GR, Inoue K, Koob GF, Rivier J, Vale W, Zorrilla EP (2002) Human urocortin II: mild locomotor suppressive and delayed anxiolytic-like effects of a novel corticotropin-releasing factor related peptide. Brain Res 943:142-150.

Valdez GR, Zorrilla EP, Rivier J, Vale WW, Koob GF (2003) Locomotor suppressive and anxiolytic-like effects of urocortin 3, a highly selective type 2 corticotropin-releasing factor agonist. Brain Res 980:206-212.

Van Pett K, Viau V, Bittencourt JC, Chan RK, Li HY, Arias C, Prins GS, Perrin M, Vale W, Sawchenko PE (2000) Distribution of mRNAs encoding CRF receptors in brain and pituitary of rat and mouse. J Comp Neurol 428:191-212.

Venihaki M, Sakihara S, Subramanian S, Dikkes P, Weninger SC, Liapakis G, Graf T, Majzoub JA (2004) Urocortin III, a brain neuropeptide of the corticotropin-releasing hormone family: modulation by stress and attenuation of some anxiety-like behaviours. J Neuroendocrinol 16:411-422.

Vochteloo JD, Koolhaas JM (1987) Medial amygdala lesions in male rats reduce aggressive behavior: interference with experience. Physiol Behav 41:99-102.

Winslow JT, Insel TR (2004) Neuroendocrine basis of social recognition. Curr Opin Neurobiol 14:248-253. 